\title{
2. DIE STELLUNG DER KARDINÄLE UNTER CLEMENS VI.
}

Die Kardinäle waren und sind die nach dem Papst höchsten Würdenträger der Kirche und fungieren als dessen engste und wichtigste Berater ${ }^{1}$. Unterteilt in die Gruppen der Kardinalbischöfe, -priester und -diakone, werden sie allein vom Papst ernannt und genießen gewisse, allein ihnen zustehende Prärogativen. Das vornehmste Recht besteht bis zum heutigen Tag in der Papstwahl, die exklusiv von dem im Konklave versammelten Kardinalskolleg vorgenommen wird.

Der Ursprung der Bezeichnung "Kardinal« ist umstritten und wird sowohl auf das Substantiv »cardo (Türangel) $^{2}$ als auch auf das Verb »incardinare « zurückgeführt. Im ersteren Fall wird auf Kleriker verwiesen, die in einer bestimmten Kirche entweder beständig administrative Aufgaben erfüllen oder als Vorsteher innerhalb einer Pfarrei bzw. einer Diözese amtieren. Im zweiten Falle sind Kleriker angesprochen, die in einer anderen Kirche als derjenigen, für die sie eigentlich ordiniert worden sind, ihren Dienst verrichten, die mithin einer anderen Kirche incardiniert worden sind. Spätestens seit Ende des 7. Jahrhunderts wurden die cardinales als Hauptakteure der Liturgie inner-

1 Vgl. Art. Cardinal (Auguste Molien), in: DDC 2 (1937) Sp. 1310-1339; Art. Kardinal/ Kardinalskollegium (Erwin GATz), in: TRE 17 (1988) Sp. 628-635; Art. Cardinali (Pierre JugIE), in: Dizionario storico del Papato 1 (1996) S.251-255. Arbeiten, die sich mit der Stellung des Kardinalats im 14. Jahrhundert auseinandersetzen, sind rar, vgl. SCHELENZ, Studien zur Geschichte des Kardinalats; HofManN, Kardinalat und kuriale Politik; GulLLEMAIN, Cour pontificale, S. 181-276; John F. BRODERICK, The sacred college of cardinals: size and geographical composition (1099-1986), in: AHP 25 (1987) S. 7-71; vgl. zu Entstehung und Entwicklung des Kardinalkollegs im Hochmittelalter KLEWTT, Entstehung des Kardinalskollegiums, S. 115-221; Harry G. HYNEs, The privileges of cardinals. Commentary with historical notes, Washington 1945; Stephan KUTTNER, Cardinalis. The History of a canonical concept, in: Traditio 3 (1945) S. 129-141; Michel ANDRIEU, L'origine du titre de cardinal dans l'Église Romaine, in: Miscellanea Giovanni Mercati, Bd.5, Città del Vaticano 1946, S. 113-144; Carl Gerold Fürst, Cardinalis. Prolegomena zu einer Rechtsgeschichte des römischen Kardinalskollegiums, München 1967; AlBerigo, Cardinalato e collegialità; Luchesius SPÄTLING, Kardinalat und Kollegialität. Zum gleichnamigen Buche von G. Alberigo, in: Antonianum 45 (1970) S. 273-286; John A. WATT, The constitutional law of the College of Cardinals: Hostiensis to Johannes Andreae, in: Medieval Studies 33 (1971) S. 127-157; Agostino Paravicini Bagliani, Cardinali di curia e "familiae* cardinalizie dal 1227 al 1254, Padua 1972; GANZER, Das römische Kardinalkollegium; Lara CASTlLlo, La institucion del cardenalato en perspectiva historico-juridica, in: Boletin de la Academia Nacional de la Historia 68 (1985) S. 915-928; Bernard Gulllemain, Cardinaux et société curiale aux origines de la double élection de 1378, in: Genèse et débuts du Grand Schisme d'Occident, Paris 1980, S. 19-30; Aldo RossI, Il Collegio Cardinalizio, Città del Vaticano 1990; Christoph WEBER, Senatus divinus. Verborgene Strukturen im Kardinalskollegium der frühen Neuzeit (1500-1800), Frankfurt a. M. 1996.

2 Nicolaus von Bibra, Occultus Erfordensis, hg.v. Christiane MundHenk, Weimar 1997, S.318. 
halb der Römischen Kirche angesehen, band man die Begrifflichkeit immer enger an die Kirche von Rom.

Der eigentliche Aufstieg des Kardinalskollegs begann jedoch erst in der Zeit des Reformpapsttums ${ }^{3}$. Für die Verwirklichung seiner ehrgeizigen und weitgespannten Reformpläne war Gregor VII. (1073-1085) in besonderem Maße auf enge Kollaboration mit den Kardinälen als seinen engsten Mitarbeitern angewiesen. Die Aufgabenbereiche begannen sich zu verlagern: neben die weiterbestehenden liturgischen Funktionen traten diplomatische Missionen im Dienste des Papstes. Des weiteren oblag den Kardinälen bereits zu diesem Zeitpunkt die Prüfung von an der Kurie anhängigen Verfahren. Eine erste Bestätigung ihres Machtzuwachses war bereits mittels der von Nikolaus II. 1059 promulgierten Bulle In nomine Domini erfolgt. Allein den Kardinalbischöfen oblag fortan die Wahl des neuen Papstes ${ }^{4}$. Kardinalpriester und -diakone, der Klerus und das Volk von Rom hatten die vorgenommene Wahl lediglich zu bestätigen. Der bisher beherrschende Einfluß des Kaisers und der stadtrömischen Adelsgeschlechter wurde somit auf ein Minimum reduziert. Frucht des Wibertinischen Schismas war der Aufstieg der Kardinalpriester in den Rang von Papstwählern. Dazu wurde die Bulle Nikolaus' II. modifiziert. Alle kardinalizischen ordines, mithin unter Einschluß der Kardinaldiakone, waren zum ersten Mal 1113 an einer Papstwahl gemeinsam beteiligt. Die Ergänzung des Wahlrechts mittels Festschreibung der Gleichwertigkeit aller drei ordines und Festlegung der zu einer gültigen Wahl nötigen Zweidrittelmehrheit erfolgte 1179 auf dem Dritten Laterankonzil. Spätestens jetzt kann von einem voll ausgebildeten Kardinalskolleg gesprochen werden ${ }^{5}$. Änderungen innerhalb des Wahlprocederes wurden auch später noch vorgenommen, so beispielsweise die von Gregor X. 1274 auf dem Zweiten Konzil von Lyon verfügte Einrichtung des Konklaves, das die Dauer der Papstvakanzen auf ein Minimum reduzieren sollte ${ }^{6}$. Waren die institutionellen Grundlagen des Kardinalats somit gelegt, sah man sich nun vor die Herausforderung gestellt, eine biblisch kaum legitimierte Institution mit einem ekklesiologischen Überbau zu versehen. Der Beitrag, den Petrus Damiani zur Formulierung einer Theologie des Kardinalats lieferte, ist dabei

3 Vgl. MaleczeK, Papst und Kardinalskolleg, S.54, 207-246; Ganzer, Kardinalkollegium, S. 157-164.

${ }_{4}^{4}$ Hans-Georg Krause, Das Papstwahldekret von 1059 und seine Rolle im Investiturstreit, Rom 1960; Detlev JASPER, Das Papstwahldekret von 1059. Überlieferung und Textgestalt, Sigmaringen 1986.

5 Vgl. Bernhard Schimmelpfennig, Das Papsttum im Hohen Mittelalter: eine Institution?, in: Institutionen und Geschichte. Theoretische Aspekte und mittelalterliche Befunde, hg.v. Gert MELviLle, Köln, Weimar, Wien 1992, S. 209-229, hier S. 220.

6 Lorenzo SPinelli, La vacanza della Sede Apostolica dalle origini al Concilio Tridentino, Mailand 1955; Enzo PETRUCCI, Il problema della vacanza papale e la costituzione Ubi periculum di Gregorio X, in: Atti del Convegno di studio. VII centenario del $1^{\circ}$ conclave (1268-1271), Viterbo 1975, S.69-96. 
immer noch umstritten ${ }^{7}$. Die Kanonistik schwieg sich erstaunlich lange über die rechtliche Stellung der Kardinäle aus. Die einzige kirchenrechtlich definierte Aufgabe fand sich lange Zeit lediglich im Papstwahldekret von 1059 und seiner Ergänzung 1179. Erst seit der Mitte des 13. Jahrhunderts wurde das Bild vom Haupt und seinen Gliedern, d.h. vom Papst und seinen Kardinälen, Gemeingut der Kanonisten - insbesondere der Hostiensis lieferte mit seinem Kommentar zur Dekretale Ad liberandam einen wichtigen Beitrag zur Klärung des Verhältnisses zwischen caput und $m e m b r a^{8}$. Im Falle Clemens' VI. ist in dieser Beziehung ein Brief von großer Bedeutung, der die Kurie am 15. März 1344 verlie $\beta$ und an den neukreierten Pierre Bertrand junior gerichtet war'. Die Aufforderung an Bertrand, sich unverzüglich nach Avignon zu begeben, wird darin von Reflexionen über Stellung und Bedeutung des Kardinalats begleitet. Der Papst bekennt, daß er sich in seiner Kreationspraxis an Moses orientiere, der dem Rat seines Verwandten Jetro folgte und sich viros prudentes et Deum timentes circa regendam plebem Israeliticam erwählte ${ }^{10}$. Als Papst sei er alleine nicht dazu in der Lage, das onus spiritualis regiminis zu tragen, und bedürfe deshalb der Mitarbeit von auxiliatores ${ }^{11}$ und coadjutores ${ }^{12}$, die utique potentes in opere et sermone seien, die veritatem et iustitiam diligant und avaritiam odiant. Die nach profundis meditationibus getroffene Entscheidung zugunsten des Pierre Bertrand sei freilich nicht durch ihn allein, sondern in Absprache mit den übrigen Kardinälen erfolgt ${ }^{13}$. Damit waren die Kardinäle in ihrem Konsultationsrecht bestätigt worden. Pierre Bertrand wurde ad car-

7 Vgl. Giuseppe Alberigo, La collégialité épiscopale selon quelques théologiens de la papauté, in: La collégialité épiscopale. Histoire et théologie, Paris 1965, S. 183-221; AlBERIGO, Cardinalato, S.39-46; Michel Fors, I compiti e le prerogative dei cardinali vescovi secondo Pier Damiani nel quadro della sua ecclesiologia primaziale, in: AHP 10 (1972) S. 25-105; SPÄTLING, Kardinalat und Kollegialität, S. 278.

8 Vgl. Alberigo, Cardinalato, S. 98-107, 144-157 (Ausführungen zur Kanonistik des 14. Jahrhunderts); Joseph LECLER, Pars corporis papae. Le Sacré Collège dans l'ecclésiologie médiévale, in: L'homme devant Dieu. Mélanges offerts au Père Henri de Lubac, Lyon 1967, S. 183-198; MALECZEK, Papst und Kardinalskolleg, S.270-283; WooD, Clement VI, S.116-118; hierzu auch John van ENGEN, From practical theology to divine law: the work and mind of medieval canonists, in: Proceedings of the Ninth International Congress of Medieval Canon Law, hg.v. Peter Landau, Joers Mueller, Vatikan 1997 (Monumenta Iuris Canonici, series C Subsidia, 10), S. 873-896.

9 Vgl. Kap. 4.3.; Lettres Clément VI, n. 726.

10 Ex 18.

11 Vgl. Wortkonkordanz zum Decretum Gratiani, bearb. v. Timothy ReUTER, Gabriel SILAGI, Bd. 1, München 1990, S. 388f. Der Begriff auxiliator taucht dort als juristischer Terminus nicht auf: unter dem Lemma auxiliari findet sich zumeist der Verweis auf den Ablativus Absolutus deo auxiliante.

12 Vgl. ibid., S.675. Unter dem Lemma coadiutor finden sich fünf Einträge, von denen immerhin vier das Faktum behandeln, daß einem Bischof senectute gravato ein coadiutor zur Seite gestellt wird.

13 Das topische Formelgut matura deliberatione cum fratribus nostris prehabita oder ein de dictorum fratrum consilio wird angeführt. 
dinalatus honorem berufen, in ein Ehrenamt, das vergleichbar mit dem Papstamt eine Last (onus) beinhalte, die reverenter übernommen werden solle. Die auf ihn wartenden Aufgaben bestünden darin, una nobiscum et eisdem fratribus divinis obsequiis et Ecclesie Romane serviciis vacaturus, also im Dienst an Gott und der von Gott selbst eingesetzten Institution Kirche ${ }^{14}$. Was der Papst insbesondere unterstrich, war seine potestas, die nicht so sehr in der Kreation von Kardinälen als in der Lösung von Banden bestand, die einen Bischof an seine Diözese fesselten. Auch in den Diözesen vor Ort schien man mit dem Einfluß, den die Kardinäle auf die Entscheidungsfindungen des Papstes auszuüben vermochten, zu rechnen ${ }^{15}$. Die verstärkte Neigung der Päpste, insbesondere Urbans II., das Kolleg bei allen wichtigen zur Entscheidung anstehenden Fragen zu konsultieren, führte zur Ausbildung eines regelmäßig tagenden Konsistoriums, zu dem Papst und Kardinalskolleg in den dafür bestimmten Räumlichkeiten des Papstpalastes zusammentraten ${ }^{16}$. Man unterschied früh zwischen einem consistorium secretum, an dem ausschließlich die Kardinäle teilnahmen, und einem consistorium publicum, zu dem auch andere Personen wie Botschafter und hohe kirchliche Würdenträger zugelassen waren. Die Möglichkeit, zu Problemen und anstehenden Entscheidungen Stellung zu nehmen, hatte jedes Mitglied des Kardinalskollegs, jedoch unterlag die Plazierung eines Wortbeitrags einem strengen Reglement, bei dem die Hierarchisie-

14 Fast identische Formulierungen verwandte Benedikt XII. 1338 in einer ähnlichen Angelegenheit, vgl. Lettres Benoît XII autres que la France, n.2142. Die Beschreibung der von den Kardinälen eingeforderten ydoneitas verzichtet lediglich auf die Feststellung potentes opere et sermone und ersetzt diesen Sachverhalt durch ein Deum timentes.

15 Vgl. Jean de Hocsem, Chronique, hg.v. Godefroid KuRTH, Brüssel 1927, S. 334-338. In einem Brief des Kathedralkapitels von Lüttich vom 23. August 1346 wurden die Kardinäle um Hilfe in den Auseinandersetzungen wegen einer strittigen Bischofswahl gebeten. Dabei wurde betont, daß die Kardinäle nicht allein vom Papst, sondern gleichsam von Christus selbst ernannt würden. Man scheute sich also nicht, die Kardinäle mit einem transzendenten Nimbus zu umgeben und sie somit verdächtig nahe an die Gestalt des vicarius Christi selbst zu rücken. Als Hauptaufgabe wurde das gemeinsame Vorgehen mit dem Papst gegen die scandala der Welt benannt: Vos igitur, misericordie patres, quos ad hoc Christus et Christi vicarius principes constituit orbis terre ut cooperantes eidem verbo virtutis et opere de mundo scandala tolleretis [...]; vgl. zu weiteren Beispielen WOOD, Clement VI, S.101f.

16 Die Ausschlußtage listet das Zeremoniale von Kardinal Stefaneschi auf, vgl. Marc DYKMANS (Hg.), Le cérémonial papal de la fin du Moyen Âge à la Renaissance, Bd.2: De Rome en Avignon ou le cérémonial de Jacques Stefaneschi, Brüssel, Rom 1981, S. 412-424; DERS., Mabillon et les interpolations de son Ordo Romanus XIV, in: Gregorianum 47 (1966) S.316-342. Grundsätzlich wurde auf die Abhaltung von Konsistorien am Donnerstag und am Sonntag, in der Zeit von Silvester bis Epiphanias, von Palmarum bis zum Sonntag nach Ostern - dies galt freilich nicht, wenn Kardinalskreationen anstanden -, an Christi Himmelfahrt, den vier Hauptmarienfesten und anderen Gedenktagen verzichtet. Nur in Ausnahmefällen traf man sich zu Beratungen während der Sommerpause, die sich gewöhnlich vom 29. Juni (Fest des Apostels Petrus) bis zum 15. September, der Oktav der Geburt der Jungfrau Maria, erstreckte. Vgl. auch Jordan, Le Sacré Collège, S. 545-559; MALECZEK, Papst und Kardinalskolleg, S. 298-312. 
rung des Kollegiums in die drei bekannten ordines zum Tragen kam. Das Recht, sich äußern zu können, lag zunächst beim Prior der Kardinalbischöfe und ging dann auf den Subprior und die restlichen Kardinalbischöfe über. Es folgte der Prior der Kardinalpresbyter, dem sich die übrigen Presbyter anschließen konnten. An letzter Stelle standen die Kardinaldiakone ${ }^{17}$. Wortbeiträge sollten nach Möglichkeit nicht unterbrochen werden. Dieses Recht stand allein dem Papst zu ${ }^{18}$. Die Bedeutung des Konsistoriums wuchs mit der fortschreitenden Zentralisierung der päpstlichen Verwaltung. So wurden ihm beispielsweise wichtige zur Entscheidung anstehende Fragen juristischer Natur unterbreitet. Entscheidungsbefugnisse lagen dabei nicht nur im Bereich von Exkommunikationen, der Errichtung neuer Diözesen, strittiger Bischofswahlen oder Exemtionen, sondern auch auf dem Gebiet des Prozeßrechts gegenüber Bischöfen und der Interdependenz zwischen Kaiser und anderen weltlichen Gewalten. Spätestens seit Eugen III. (1145-1153) wurden neben der Aussendung von Kardinallegaten auch anstehende Kardinalserhebungen im Konsistorium diskutiert. In der Mitte des 14. Jahrhunderts waren es vier zentrale Punkte, an denen sich die Partizipation der Kardinäle an den laufenden Geschäften der Kurie manifestierte ${ }^{19}$. Neben die Behandlung von Fragen bezüglich der kirchlichen Disziplin ${ }^{20}$ - unter Einschluß von Kanonisationen ${ }^{21}$ - traten ganz allgemein Mitsprachrechte bezüglich der kanonischen Jurisdik-

17 DykMans, Cérémonial II, S. 472.

18 Ibid.: Nullus debet consulentem interrumpere nisi papa si vult [...].

19 Wood, Clement VI, S. $97 \mathrm{f}$.

20 Hierunter fiel das weite Gebiet der Devianzen und Häresien. Jean de Roquetaillade, von Clemens VI. wegen solcher Vorwürfe in Haft genommen, schildert in seinen Schriften das Bemühen einiger Kardinäle, darunter Élie Talleyrand und Guillaume Court, Licht in das Dunkel der gegen ihn gerichteten Beschuldigungen zu bringen, vgl. Jeanne BIGNAMIODIER, Jean de Roquetaillade (de Rupiscissa). Théologien, polémiste, alchimiste, in: HLF 41 (1981) S. 75-240, hier S. 82, 99, 103.

21 Die Mitwirkung der Kardinäle bei der einzigen, von Clemens VI. während seines Pontifikates vorgenommenen Heiligsprechung ist bezeugt, vgl. Odorico RAYNALDI, Annales ecclesiastici, Bd.25, a.a. 1347, S.436: Modus qui communiter servari consuevit circa canonizationem alicujus sancti: Dominus noster papa consuevit hoc proponere inter fratres, scilicet cardinales. Et de ipsorum consilio committit aliquibus episcopis patriae illius, qui dicitur sanctus, vel aliis personis authenticis, honestis, discretis et incorruptibilibus, ut inquirant de fama et devotione populi [...]. Dominus papa iterum requirit consilia cardinalium, et de ipsorum consilio definit in consistorio utrum secundum relata sit inquisitio predicta super veritate committenda vel non. Bei dem neu zur Ehre der Altäre Erhobenen handelte es sich um den Heiligen Ivo, den Patron der Juristen, vgl. zu ihm Guy-Alexis LOBINEAU, Les vies des Saints de Bretagne, Bd.3, Paris 1837, S. 1-58; Arthur de la Borderie, Monuments originaux de l'histoire de saint Yves, Saint-Brieuc 1887, S. 301-435; Henri QUEFFÉLEC, Saint Yves, Paris 1991; Jean Christophe Cassard, Saint Yves de Tréguier: un saint du XIII' siècle, Paris 1992; Jean LE MAPPIAN, Saint Yves, patron des juristes, Rennes 1997; Annette RIECK, Der Heilige Ivo von Hélory (1247-1303). Advocatus pauperum und Patron der Juristen, Frankfurt a. M. 1998; Jussi HANSKA, St Yves de Tréguier as a preacher, in: Medieval Sermon Studies 49 (2005) S. 27-37; vgl. auch Mollat, Contribution, S.95f. 
tion $^{22}$, der politisch-administrativen und der finanziell-ökonomischen Angelegenheiten der Kirche ${ }^{23}$. Eine kanonisch festgelegte Konsultationspflicht des Papstes bestand jedoch nicht. Er war lediglich gehalten, sich des Sachverstands seiner Kardinäle bei der Lösung anstehender Probleme zu bedienen. Im Bereich der spiritualia verfügten die Kardinäle über weitere Privilegien. Nicht nur in ihrer Funktion als Legat waren sie beispielsweise befugt, Ablässe von 100 Tagen Dauer zu gewähren ${ }^{24}$.

Über die Präsenz der Kardinäle in den Konsistorien geben nur wenige Quellen Auskunft ${ }^{25}$. Aufgrund der Schwerfälligkeit der Beratungen und der daraus resultierenden extrem langsamen Entscheidungsfindung wurden zur ersten Begutachtung juristischer Probleme Kommissionen eingerichtet, die zumeist aus drei Kardinälen bestanden. Lediglich die dort erzielten Ergebnisse wurden dem Konsistorium zur abschließenden Diskussion unterbreitet. Dies führte in der Tat zu einer herausgehobenen Stellung einiger weniger Purpurträger, deren Arbeit in unterschiedlichen Kommissionen immer wieder belegt ist, was sich insgesamt jedoch ungünstig auf die Machtstellung des Kardinalats als Gesamtkörper auswirkte ${ }^{26}$. Im Falle Clemens' VI. beschäftigten sich beispielsweise Kardinalskommissionen 1346 mit der Rechtmäßigkeit der Wahl Karls IV. zum deutschen König 27,1348 mit der Frage, ob Johanna I. tat-

$22 \mathrm{Vgl}$. Mollat, Contribution, S. 80-93. Auf den vermeintlichen Einfluß der Kardinäle verweist Jean de Hocsem, Chronique, S. 325 wenn er die Kirche von Lüttich 1343 an der Kurie appelieren läßt. An die Kardinäle gerichtet, schwingt man sich zu folgender Behauptung auf: Ad illos nimirum devotissima filia vestra Leodiensis ecclesia cum civitate [...] cogitur habere recursum, quos celi arideque conditor ad hoc constituit principes orbis terre, ut oppressorum iusticiam apud vicarium promoveant Jesu Christi. Kardinäle sollen die Rechte der Unterdrückten vor dem Papst vertreten, erfüllen somit eine Funktion, die im Himmel von den Heiligen als intercessores wahrgenommen wird.

$23 \mathrm{Vgl}$. Gaignard, Le gouvernement, S. 208-210; Guillemain, Cour pontificale, S. 225-241; Paul Maria BaumgarTen, Untersuchungen und Urkunden über die Camera Collegii Cardinalium für die Zeit von 1295 bis 1437, Leipzig, Berlin 1897, S.XXXIIII-XLI; Franz GillmanN, Die Resignation der Benefizien, in: Archiv für Katholisches Kirchenrecht 80 (1900) S. 50-79, 346-379, 523-569, 665-708.

24 Marc Dykmans, Jacques Stefaneschi, élève de Gilles de Rome et cardinal de Saint-Georges (vers 1261-1341), in: RStChI 29 (1975) S.536-554, hier S. 551: Et concedit etiam centum dies ex privilegio cardinalium.

${ }^{25}$ Für den Pontifikat Clemens' VI. ist einschlägig Helmut SCHRÖDER, Die Protokollbücher der päpstlichen Kammerkleriker 1329-1347, in: Archiv für Kulturgeschichte 27 (1937) S. 121-286. Die Partizipation der Kardinäle am politischen Tagesgeschäft, auf die in früheren Zeiten durch die Subskriptionen auf den päpstlichen Bullae maiores rückgeschlossen werden konnte, ist im 14. Jahrhundert durch den Wegfall dieser Unterschriften schwieriger zu rekonstruieren, vgl. Bruno KatTerBaCH, Wilhelm PEITz, Die Unterschriften der Päpste und Kardinäle in den Bullae maiores vom 11. bis 14. Jahrhundert, in: Miscellanea Francesco Ehrle. Scritti di storia e paleografia, Bd.4, Rom 1924, S.177-274; MALECZEK, Papst und Kardinalskolleg, S. 320-322.

26 Auf diesen Umstand hatte bereits SCHELENZ, Studien, S. 48, hingewiesen.

27 Die Kommission bestand aus sechs Kardinälen, vgl. MGH, Constitutiones, Bd. 8, S.163. 
sächlich Schuld am Tod ihres Gatten Andreas habe ${ }^{28}$, untersuchten 1349, wie eine Invasion des Königs von Ungarn ins Königreich Neapel verhindert werden könne ${ }^{29}$, und waren 1351 gar mit der Ausarbeitung einer neuen Verfassung für die Stadt Rom betraut ${ }^{30}$. Die Untersuchung bestimmter Streitfälle konnte wie im Falle des sich von 1346-1348 hinziehenden Prozesses gegen Francesco Ordelaffi, Tyrann von Forlì, mit dem Adémar Robert betraut wurde, einzelnen Kardinälen übertragen werden ${ }^{31}$. Bernard d'Albi urteilte im Streit, der Kapitel und Bischof von Lombez entzweite ${ }^{32}$. Die Kurie versuchte, die Kardinäle auch in das administrative Alltagsgeschäft miteinzubinden: Bertrand du Pouget und Annibaldo Ceccano konnten damit beauftragt werden, die Reparatur der Rhônebrücke zu überwachen ${ }^{33}$.

Seit Gregor IX. (1227-1241) war die Kardinalswürde mit einer Residenzpflicht an der Kurie verbunden ${ }^{34}$. Dieser Papst verfügte ebenfalls, daß VeräuBerungen päpstlichen Patrimonialbesitzes nur mit Zustimmung der Kardinäle erfolgen könnten ${ }^{35} .1289$ gewährte Nikolaus IV. mittels der Bulle Coelestis altitudo den Kardinälen die Hälfte aller regulären Einkünfte der Römischen Kirche. Dazu zählten auch die renditeträchtigen servitia communia. $\mathrm{Zu}$ diesen Einkünften kamen die Benefizialerträge, Zahlungen weltlicher Souveräne ${ }^{36}$,

28 Vgl. Kap. 5.2.2.1.

29 Vgl. Kap. 5.2.4.

30 Petrarca, Familiares, 11,16 und 11,17. Der Dicher mahnte die vier Kardinäle, bei all ihren Entscheidungen die Größe Roms niemals aus dem Blick zu verlieren; vgl. zu weiteren Kommissionen beispielsweise Paul-Émile GIRAud, Essai historique sur l'abbaye de S. Barnard et sur la ville de Romans, Bd.2, 1866, Anhang (Appendice au cartulaire de Romans et nouvelles pièces justificatives inédites servant de preuve à la deuxième partie), S.384.

31 Vgl. zu dieser Untersuchung ausführlich MoLLaT, Contribution, S. 82-88.

32 Adrien Clergeac, Différend entre l'évêque de Lombez et son chapitre en cour d'Avignon, in: Revue de Gascogne (1904) S. 563-568.

33 Vgl. SCHÄFER, Ausgaben Klemens VI., S. 199, $230 f ., 286$.

34 Zuvor waren auch Äbte wichtiger Abteien oder Bischöfe herausragender Diözesen mit dem Ehrentitel Kardinal bedacht worden, vgl. Klaus GANZER, Die Entwicklung des Auswärtigen Kardinalats im Hohen Mittelalter. Ein Beitrag zur Geschichte des Kardinalkollegiums vom 11. bis 13. Jahrhundert, Tübingen 1963; Carl Gerold FÜrST, Die »geborenen « Kardinäle, in: Zeitschrift für Katholische Theologie 88 (1966) S. 51-74; Klaus GANZER, Zur Frage der sogenannten "geborenen « Kardinäle von Vendôme, in: ZKG 78 (1967) S. 340-345; GANZER, Kardinalkollegium, S.179-181; Carl Gerold FÜRST, I cardinalati non romani, in: Le istituzioni ecclesiastiche della »societas christiana« dei secoli XI-XII. Atti della quinta settimana internazionale di studio Mendola (26-31 agosto 1971), Mailand 1974, S. 185-202.

35 Regesta pontificum Romanorum, hg. v. August PotTHASt, Berlin 1874, n. 9368.

36 Niccold Capocci erhielt als protettore der Stadt Florenz ebenso wie Rinaldo Orsini umfangreiche Zahlungen, vgl. Carlo Cipolla, Francesco Petrarca e le sue relazioni colla corte avignonese al tempo di Clemente VI, Turin 1909, S.63; Mollat, Papes d'Avignon, S. 498. Auch Bertand de Deux und Gui de Boulogne profitierten von der Großzügigkeit der Signoria. Raymond de Farges erhielt Zuwendungen vom englischen König, vgl. RYMER, Foedera, Bd.5, S.309, 439; Ploger, England, S.248f. mit einer Auflistung der von Ed- 
Geschenke des Papstes ${ }^{37}$ und andere Formen monetärer Zuwendungen hinzu ${ }^{38}$. Die Verwaltung und Verteilung der den Kardinälen zustehenden Gelder lag in den Händen der Camera collegii cardinalium, einer Verwaltungsbehörde, an deren Spitze der Kardinalkämmerer stand ${ }^{39}$. Die finanzielle Situation des Kollegs war um 1350 derart günstig, daß Clemens VI. bei ihm eine Anleihe in Höhe von 16000 Goldgulden aufnehmen konnte ${ }^{40}$. Einzelne Mitglieder hatten Teile ihres Vermögens renditeträchtig angelegt, waren wie im Falle des Gozzo da Rimini jedoch auch vor Verlusten infolge von Bankzusammenbrüchen nicht gefeit ${ }^{41}$. Hugues Roger hinterließ bei seinem Tod einen großen Bestand an gemünztem Geld ${ }^{42}$. Einschneidende Veränderungen in der personellen Zusammensetzung des Kollegs fanden zu Beginn des 14. Jahrhun-

ward III. bedachten Kardinäle - für den Zeitraum von 1342-1362 immerhin 13 Personen; Kap. 9.2.42. Guillaume d'Aigrefeuille profitierte vom Wohlwollen des Königs von Aragon und erhielt jährlich 500 Gulden, vgl. Kap. 9.2.23. Der französische König gewährte Bernard d'Albi eine lebenslange Leibrente, vgl. Baluze/Mollat, Vitae II, S.325; Kap. 9.2.7.

37 Das Wahlgeschenk Clemens' VI. an die Kardinäle betrug 108000 Goldgulden, vgl. hierzu SchäFEr, Ausgaben Klemens VI., S. 197; Paul Maria BaumgarTen, Miscellanea Cameralia II. Wahlgeschenke des Papstes an das heilige Kollegium, in: Römische Quartalschrift 22 (1908) S. 36-55, hier S. 37f. Üblich waren Geschenke in Naturalien zu Weihnachten und Ostern. Die Kardinäle konnten sich an Hasen, jungen Böcken, Ziegen, Schweinen u.ä. erfreuen, vgl. ScHÄFER, Ausgaben Klemens VI., S. 209, 239, 265f., 269, 295, 363, 368f., 423f., 443, 457, 466, 478. Rinaldo Orsini bekam anläßlich seiner Kreation gar gewisse iocalia geschenkt, deren Weiterverkauf sich als ausgesprochen schwierig erwies, vgl. Kap. 9.2.43.

38 Vgl. Mollat, Contribution, S.61-72. Die Gesandten der Hansestadt Hamburg versuchten kontinuierlich, die Entscheidungen des Konsistoriums zu ihren Gusten zu beeinflussen. Zahlungen von 150 Florin an Guillaume de la Jugee und von 100 Florin an Galhard de la Mothe sind belegt, vgl. Theodor SCHRADER, Die Rechnungsbücher der hamburgischen Gesandten in Avignon 1338 bis 1355, Hamburg, Leipzig 1907, S. 88, 93, 110. Gilles Rigaud bezog von seiner alten Abtei ein Jahrgeld von 1000 Pfund, vgl. RS 23, fol.272r; Kap. 9.2.18. Guillaume Court erhielt vom Zisterzienserorden eine jährliche Zahlung von 3000 Florin, vgl. Lettres communes Benoît XII, n. 8146; Kap. 9.2.22. Der schier unstillbare Finanzbedarf der Kardinäle war Gegenstand satirischer Überzeichnung, vgl. Franz HELFENBERGER, Drei lateinische Gedichte des XIII. Jahrhunderts, in: Historisches Jahrbuch 48 (1928) S.230-280; Tractatus Garsiae or the translation of the relics of SS. Gold and Silver, hg.v. R. M. ThOMSON, Leiden 1973.

39 Paul Maria Baumgarten, Untersuchungen und Urkunden über die Camera Collegii Cardinalium für die Zeit von 1295 bis 1437, Leipzig, Berlin 1897; Johann Peter KIRSCH, Die Finanzverwaltung des Kardinalkollegiums im XIII. und XIV.Jahrhundert, Münster 1895; Mollat, Contribution, S. 72-80.

40 Die Summe sollte zur Finanzierung militärischer Operationen in der Romagna eingesetzt werden, vgl. LuLVĖs, Machtbestrebungen, S. 95; VoNES, Urban V., S. 104-106. Auch Gregor XI. lieh sich Geld bei seinen Kardinälen. Überliefert ist eine Kreditaufnahme bei Kardinal Guillaume de la Jugée in Höhe von 20000 Florin, vgl. Kap. 9.2.25.

41 Gozzo hielt eine Einlage in Höhe von 745 Florin im Bankhaus der Bardi, vgl. Kap. 9.2.20.

42 Vgl. BaluZE/Mollat, Vitae IV, S. 127-131, vgl. Kap. 9.2.26. 
derts statt, wo innerhalb weniger Jahre die numerische Übermacht der italienischen Purpurträger gebrochen und durch eine französische Mehrheit ersetzt wurde 43 .

Über das Procedere einer Kardinalskreation und die dabei zu beobachtende Interaktion zwischen Papst, Kardinalskolleg und neu zu kreierenden Purpurträgern gibt keine Quelle besser Auskunft als das zwischen 1300 und 1340 wohl von Kardinal Jacopo Stefaneschi verfaßte Zeremoniale ${ }^{44}$. Darin ist ein umfangreiches Kapitel den in Zusammenhang mit Kardinalskreationen stehenden Fragen gewidmet ${ }^{45}$. Im Gegensatz zur Aussendung von Legaten, die das gesamte Jahr über erfolgen konnte, war die Ernennung von Kardinälen an bestimmte liturgische Zeiten gebunden. Lediglich in den Quatemberwochen (ieiunia quatuor temporum), in vier über das Jahr verteilten Fasten- und Bußwochen, waren Kreationen vom Zeremoniell her überhaupt vorgesehen ${ }^{46}$. Der zur Verfügung stehende zeitliche Rahmen war damit relativ eng. Am Mittwoch einer Quatemberwoche wurden die im Konsistorium versammelten Kardinäle vom Papst nach einer kurzen Ansprache - faciendo ibi primitus aliqualem brevissimam collationem - befragt, ob eine neue Kreation statthaft sei. Nach der Beantwortung des »Ob« richtete sich der Blick des Papstes auf die Anzahl der Neuzukreierenden. Erst danach konnten sich die Kardinäle zu einzelnen möglichen Kandidaten äußern. Die diesbezüglichen Erörterungen fanden allerdings nicht mehr am Mittwoch, sondern zwei Tage später statt und folgten einem strengen Ablauf. Der Papst, flankiert vom ältesten Kardinalbischof, empfing jeden Kardinal einzeln, nannte ihm die Namen möglicher Kan-

43 Im 12. Jahrhundert hatte das Verhältnis Italiener - Franzosen noch bei $80 \%-12 \%$, im 13. Jahrhundert bei $65 \%-22 \%$ gelegen, um sich zur Zeit des Avignonesischen Papsttums mit einem Verhältnis von $10 \%-85 \%$ umzukehren.

44 Dyxmans, Cérémonial II, S.25-131, wo sich die profundeste Biographie des Kardinals findet, der sich auf S.133-153 die Diskussion bezüglich seiner möglichen Autorschaft anschließt. Dykmans sieht in Stefaneschi den Verfasser des Zeremoniale, vgl. auch DeRS., Stefaneschi, S. 541-548; Mollat, Contribution, S. 39-50.

45 Dykmans, Cérémonial II, S. 475-494 mit dem Titel: Sequuntur ceremonie et solemnitates solite servari in creatione novorum cardinalium, et in datione anuli et assignatione tituli eis facienda, et quando presbitero cardinali non noviter creato providetur de titulo episcopali cardinalari et de adventu ad curiam novorum cardinalium si sue creationis tempore a curia sint absentes.

46 Dabei handelt es sich um folgende Zeiten: erste Fastenwoche, Pfingstwoche, Woche nach dem Fest der Kreuzerhöhung (14. September), Woche nach dem 3. Adventssonntag; vgl. zu den Quatembern Ludwig EISENHOFER, Handbuch der katholischen Liturgik, Bd. 1, Freiburg 21941, S. 482-485; Bruno KLEINHEYER, Die Priesterweihe im römischen Ritus. Eine liturgiehistorische Studie, Trier 1962, S.35-38; Hermann GroTEFEND, Taschenbuch der Zeitrechnung des deutschen Mittelalters und der Neuzeit, Hannover ${ }^{13} 1991$, S. 16. Clemens VI. schenkte der Frage um den richigen Kreationstermin insbesondere in seiner Collatio Videntibus illis elevatus est große Beachtung, vgl. Kap. 4.6.; zu den kirchenrechtlichen Aspekten vgl. Corpus iuris canonici, hg. v. Emil FRIEDBERG, 2 Bde., Graz 1879-1881, hier Bd. 1, Sp. 267-271 [künftig zitiert als FRIEDBERG]. 
didaten und bat um eine Stellungnahme ${ }^{47}$. Auf diese Konsultation, nach der immerhin mitgeteilt wurde, ob die Gesamtheit der Kardinäle oder doch nur der größere Teil den Vorschlägen des Papstes zugestimmt hatte, folgte die eigentliche Kreation ${ }^{48}$, der sich die Benachrichtigung der Neuernannten anschloß.

Der bisherige Ablauf dürfte deutlich gemacht haben, daß das Konsistorium als zu konsultierendes Gremium ohne eigenes Vorschlagsrecht zwar an der Ergänzung der eigenen Reihen beteiligt wurde, der Papst jedoch allein über die neuzukreierenden Kardinäle entschied ${ }^{49}$. Der Wert dieser den Papst nicht bindenden Konsultationen wurde an keiner Stelle besser deutlich als bei der Beantwortung der Ausgangsfrage, ob überhaupt neue Kardinäle kreiert werden sollten. Hier war es dem Papst trotz gegenteiliger Voten seiner Kardinäle möglich, so zu entscheiden, wie er es für richtig hielt ${ }^{50}$.

Am Samstag fand die eigentliche Kreationszeremonie statt. In einem Konsistorium, das durch die Präsenz der päpstlichen Kapläne, Kammerkleriker und anderer Palastbeamter zum consistorium publicum wurde, hielt der Papst eine kurze Ansprache, in der Weisheit, Treue, Klugheit und andere positive Eigenschaften der Kandidaten gewürdigt wurden ${ }^{51}$. Danach erfolgte deren eigentliche Ernennung. Erst zu diesem Zeitpunkt wurden sie, die außerhalb des Konsistorialsaals gewartet hatten, vor den Papst geführt und von ihm in einer kurzen Ansprache zu klugem und besonnenem Handeln ermahnt. Nach dem obligatorischen Fußkuß wurde von allen das Te Deum angestimmt, in dessen Verlauf sich die neuen Purpurträger zum Gebet vor den Altar begaben. Es schloß sich das osculum oris der alten Kardinäle an, dem ein erneutes osculum pedis et oris des Papstes folgte. Die Zuweisung der Sitze richtete sich streng nach den Vorgaben des jeweiligen ordo und innerhalb desselben nach der Anciennität. Nach diesem ersten Schritt, der öffentlich zelebrierten Aufnahme der Kandidaten in das Kardinalskollegium, änderte sich der Charakter

47 Dyкmans, Cérémonial II, S. 477: Dominus vero papa consuevit dicere illi cardinali et aliis post eum venientibus secundum ordinem suum: "Nos cogitavimus de talibus personis", quas ibi nominat, "dicatis quid vobis de istis vel de aliis videtur esse fiendum. « Tunc cardinalis ille et alii successive postea per ordinem suum venientes respondent quod eis videtur secundum quod Deus eis ministravit.

48 Ibid.: Quo facto, dominus papa consuevit eis dicere: „Deo gratias, nos habemus de personis concordiam omnium fratrum, vel quasi omnium, vel maioris partis«, secundum quod fuerit, nichil tamen aliud spe ipsa concordia specifice exprimendo. Et immediate ipse ibi creat cardinales, tam presentes in curia quam absentes.

$49 \mathrm{Vgl}$. Wood, Clement VI, S. 107.

50 Dykmans, Cérémonial II, S. 476: Quo facto, dominus papa consuevit dicere: $\$$ Nos sequimur consilium dicentium quod fiant vel non fiant", secundum quod melius videbitur ei fiendum.

51 Ibid., S. 478: Dominus vero papa facit ibi in presentia omnium unum brevem sermonem. In fine vero sermonis descendit per ordinem ad nominationem cardinalium, tam presentium in curia quam absentium, quos creavit, quemlibet eorum commendando de scientia, fidelitate, prudentia et aliis, prout merita cuiuslibet requirent [...]. 
des Konsistoriums: es wurde vom consistorium publicum zum consistorium secretum. Nachdem alle Nicht-Kardinäle den Saal verlassen hatten, begann die Zeremonie der aperitio oris, der »Mundöffnung «. Durch diesen symbolischen Akt erhielten die neuen Kardinäle neben dem Sitz auch Stimme innerhalb des Konsistoriums, wodurch es ihnen ermöglicht wurde, ihrer eigentlichen Aufgabe - der Beratung des Papstes - nachzukommen. Vor der eigentlichen aperitio stand jedoch die impositio silentii, ein Schweigegebot, das die volle Teilhabe der neuen Kardinäle an den Beratungen bis zum nächsten Konsistorium suspendierte. Der Tag endete mit einem gemeinsamen Festmahl, an dessen Ende die Verleihung der roten Hüte an die Neukreierten und ein gemeinsames Gebet in der Kathedrale standen.

Der folgende Tag, ein Sonntag, begann mit einem Besuch aller alten Kardinäle durch die Neukreierten, wobei das Prinzip der Anciennität durchbrochen wurde. Den neuen Purpurträgern gestand man zu, ihren Besuchspflichten nach eigenen Präferenzen nachzukommen - secundum quod cardinalibus novis magis placebit ${ }^{52}$. Frucht dieser Besuchstour sollte ein erster persönlicher Austausch zwischen den Kardinälen und eine Art Verhaltensinstruktion an die Neuzugänge sein, von der Frage geleitet, wie im Konsistorium am besten das Wort ergriffen werden könne, ohne damit den Papst oder die alten Mitglieder des Kollegiums zu verletzen. Daß diese Besuchstour im Anschluß unter umgekehrten Vorzeichen erfolgte - die neuen Purpurträger wurden von den alten besucht -, war wohl dem Bemühen um Schaffung eines stabilen $\mathrm{Zu}$ sammenhalts innerhalb des Kollegiums geschuldet.

Im nächsten Konsistorium wurde die Zeremonie der aperitio oris zum Abschluß gebracht. Tatsächlich erhielten die neuen Kardinäle nun Stimme im exklusiven Beratungsgremium des Papstes ${ }^{53}$. Gleichzeitig erfolgte die Übergabe des Rings und die Zuweisung der Titelkirche ${ }^{54}$. Das Zeremoniell ordnete ebenfalls gewisse Sonderfälle wie beispielsweise die Kreation einer von der Kurie abwesenden Persönlichkeit. Genau beschrieben wurde auch das bei einer Translation vom Ordo der Kardinalpresbyter in den Ordo der Kardinalbischöfe zu beachtende Procedere ${ }^{55}$. Die neue Würde bedingte im Idealfall ein von gegenseitiger Zuneigung und Wertschätzung getragenes Verhältnis zwi-

52 Ibid., Cérémonial II, S. 482.

53 Die offizielle Formel lautete: "Nos aperimus tibi os", vel vobis, si sunt plures, "tam in collationibus, quam in consiliis, et in electione Romani pontificis, et in omnibus actibus, tam in consistorio quam extra, qui ad cardinales spectant et quos sunt soliti exercere«, ibid., Cérémonial II, S. 484.

54 Im Zeremoniell wurde ausdrücklich vermerkt, daß sich in der Zwischenzeit die Praxis eingebürgert habe, die aperitio oris aus dem eigentlichen Konsistorium auszulagern und in der camera des Papstes vorzunehmen. Verwiesen wurde auf die 1338 duch Benedikt XII. erfolgte aperitio oris der Kardinäle Bertrand de Deux, Guillaume Court und Guillaume d'Aure.

55 Dykmans, Cérémonial II, S. 489-494; vgl. JoRdan, Sacré Collège, S.427-435; Kap. 4.5., 4.7. 
schen Papst und »Kreatur«, bezeichnete einen Adoptionsakt, der zu einer klaren Rollenzuweisung führte: der Papst als Adoptierender hatte Verfügungsgewalt über die Kardinäle als Adoptierte. Der Grad der aus diesem Akt resultierenden Unterordnung stieg, wenn es sich bei den Kreierten um Nepoten des Papstes handelte ${ }^{56}$.

Integraler Bestandteil des Zeremoniells jeder Kardinalskreation war die Zuweisung einer Titelkirche ${ }^{57}$. Diese Kirche versinnbildlichte nicht nur die enge Bindung des jeweiligen Kardinals an die Stadt Rom, sondern stellte im Idealfall eine im Vergleich zu anderen kardinalizischen Einkommensgruppen zwar schmale, aber stete Einkommensbasis des Titelinhabers dar ${ }^{58}$. Über den während des Pontifikats Clemens' VI. gültigen Bestand an Titelkirchen gibt Johannes Caballinus de Cerronibus in seiner Polistoria de virtutibus et dotibus Romanorum Auskunft ${ }^{59}$. Dieses wohl kurz nach 1345 verfaßte und

$56 \mathrm{Vgl}$. hier beispielsweise die Aussagen in den Collationes Obsecro vos und Assumpsi michi duas virgas (Kap. 4.2., 4.3.). Auch Jean de Cardaillac erwähnte in seiner Traueransprache anläßlich des Todes Clemens' VI. diesen Sachverhalt: [...] qui quamplurimos progenuit filios adoptivos in diversis gradibus Ecclesie suo tempore ordinandos [...], Sermo Mortuus est David, BN, ms. lat. 3294, fol.206v. In Hinblick auf den Nachfolger Innozenz VI. wurde betont: Iste noster Salomon [Innozenz VI.] est filius domini Clementis non propagatione, sed promotione [...], Sermo Mortuus est David, BN, ms. lat. 3294, fol.208r.

57 Vgl. PIAzzA, Gerarchia cardinalizia. Anders als es der Titel des Werkes nahelegt, handelt es sich hier nicht um eine Kollektivbiographie des Kardinalats, sondern um eine immer noch mit Gewinn zu konsultierende Überblicksdarstellung zu Entstehung und Geschichte der kardinalizischen Tituli; vgl. des weiteren Louis DUCHESNE, Notes sur la topographie de Rome au Moyen Âge, II. Les titres presbytéraux et les diaconies, in: MEFR 7 (1887) S. 216-243.

58 Die Forschungssituation in Hinblick auf Titelkirchen ist nach wie vor unbefriedigend. Der Frage, ob die Verleihung von Titelkirchen mit Bedacht geschah, vielleicht sogar politisch motiviert war, ist bisher nicht systematisch nachgegangen worden, vgl. Marius BELARDO, De iuribus S.R.E. Cardinalium in titulis, Città del Vaticano 1949. Für die Frühzeit: Charles PIETRI, Régions ecclésiastiques et paroisses romaines aux derniers siècles de l'Antiquité, in: Actes du XI' congrès international d'archéologie chrétienne, Bd. 2, Rom 1989, S. 1035-1062; Louis REEKMANS, L'implantation monumentale chrétienne dans le paysage urbain de Rome de 300 à 850 , in: ibid., S.861-915. Stark archäologisch ausgerichtet ist Johann Peter KIRSCH, Die römischen Titelkirchen im Altertum, Paderborn 1918. Über die Rechte der Kardinäle in ihren Titelkirchen handelt summarisch HYNES, The privileges of Cardinals, S. 1-17. Den profundesten Überblick über die Entwicklung der kardinalizischen Ordines bis zum 12. Jh. bietet Rudolf Hüıs, Kardinäle, Klerus und Kirchen Roms 1049-1130, Tübingen 1977 (Bibliothek des DHI Rom, 48); vgl. auch Nine R. MIEDEMA, Die römischen Kirchen im Spätmittelalter nach den "Indulgentiae ecclesiarum urbis Romae«, Tübingen 2001.

59 Johannes Caballinus de Cerronibus, Polistoria de virtutibus et dotibus Romanorum, hg. v. Marc LaUREYs, Stuttgart 1995. Das dieser kritischen Ausgabe beigegebene Vorwort stützt sich auf Hermann DienER, Johannes Cavallini. Der Verfasser der Polistoria de virtutibus et dotibus Romanorum, in: Storiografia e storia. Studi in onore di Eugenio DupréTheseider, Rom 1974, S. 151-173; vgl. auch Marc LAUREYs, Between Mirabilia and Roma Instaurata: Giovanni Cavallini's Polistoria, in: Avignon \& Naples. Italy in France - France in Italy in the fourteenth century, hg. v. M. PAde, H. Ragn Jensen, L. WaAge Petersen, Rom 1997, S. 100-115. 
Clemens VI. gewidmete Werk erhöht die drei genera cardinalium ${ }^{60}$ dergestalt, daß es sie mit den drei Hierarchien der Engel vergleicht. Dienen die Engel Gott auf unterschiedliche Weise, so versehen auch die Kardinäle ihren unterschiedlichen Dienst in der unmittelbaren Umgebung des Papstes. Die Aufgabenteilung entspricht dabei der jeweiligen Stellung in der Hierarchie. Interessant immerhin, $\mathrm{daB}$ zu einer Zeit, in der jedem Kardinalsordo dasselbe Maß an politischer Mitbestimmung zukommt, jedem Kardinal dieselben Beträge aus den kurialen Einkünften zustehen, der schwer faßbare Grad an dignitas noch immer ein wichtiges Unterscheidungskriterium und Distinktionsmerkmal darstellt ${ }^{61}$. Steigerung der persönlichen dignitas und damit Partizipation an Ehrenvorrechten lassen das Durchlaufen eines innerkardinalizischen cursus honorum verständlich werden.

Unterliegt also jeder Wechsel von einem Ordo zum andern einem politischen Kalkül des Papstes? Folgt die Zuweisung von Titelkirchen einem System oder muß man sich mit der simplen Feststellung begnügen, daß die Päpste lediglich diejenigen Titel wiederverleihen, die gerade vakant sind, Titelkirchen also zwar unverzichtbares, aber sinnentleertes Zeichen des kardinalizischen Amtes sind? Johannes Cavallini gliedert die ihm bekannten Titel wie folgt: Die Kardinalbischöfe verfügen über sechs Titel ${ }^{62}$, während den Kardinalpresbytern 28 Titel zustehen, die in Siebenergruppen den vier Patriarchalbasiliken zugewiesen werden ${ }^{63}$. Die Kardinaldiakone schließlich verfügen über $16 \mathrm{Ti}$ -

60 Ed. LAUREYs, III, 10.

61 Ibid., III, 10, 2: Episcopi enim in sollempnitatibus sunt domini pape assessores, unde ipsi soli inter cardinales cathedris utuntur. Presbyterorum vero cardinalium quilibet ebdomadam suam servans in missis et horis assistit domino papae; dyaconi vero cardinales insistunt ministeriis. Ipsi enim dyacones papam induunt eundemque sustentantes deducunt et ei circa altare deserviunt.

62 Ibid., III, 10, 3: Ostiensis, Portuensis et Sancte Ruffine, Albanensis, Sabinensis, Tusculanus, Penestrinus. Dem Kardinalbischof von Ostia, qui propter pape consecrationem dignior est aliis et pallio utitur, kommt dabei aufgrund seiner Funktion als Papstcoronator eine herausgehobene Stellung zu. Er ist nicht nur primus inter pares, sondern übertrifft alle übrigen Kardinäle durch die mit seinem Titel verbundenen Aufgaben: dignitas ist hier klar an eine Funktion gekoppelt.

63 Ibid., III, 10, 4: Presbyteri vero cardinales sunt numero XXVIII qui divisi per numerum septenarium in residuis IIII patriarchalibus ecclesiis urbis Rome debent domino pape deservire ad celebrandum.

St. Peter zugeordnete Titel: Sanctae Mariae Transtiberim; Sanctae Anastasie; Sancti Laurentii in Damaso; Sancti Marci; Sancti Martini in Montibus; Sancti Crisoconi; Sancte Cecilie in Transtiberim.

St. Paul vor den Mauern zugeordnete Titel: Sancte Sabine; Sancte Prisce; Sancte Balbine; Sanctorum Nerei et Achilei; Sancti Sixti; Sancti Marcelli; Sancte Susanne.

St. Laurentius vor den Mauern zugeordnete Titel: Sancti Laurentii in Lucina; Sancte Crucis in Ierusalem; Sancti Stephani in Celiomonte; Sanctorum Johannis et Pauli; Sanctorum IIII Coronatorum; Sancte Presedis; Sancti Petri ad Vincula.

S. Maria Maggiore zugeordnete Titel: Basilice XII Apostolorum; Sancti Ciriaci in Termis; Sancti Eusebii; Sancte Potentiane; Sancti Vitalis; Sanctorum Marcellini et Petri; Sancti Clementis. 
te ${ }^{64}$. Die besondere Stellung der Kardinalbischöfe mit dem Bischof von Ostia an der Spitze leitet sich aus ihrer vermeintlichen Funktion während der Papstvakanz her. Ihnen obliegt es, während dieser Zeit die Lasten der Gesamtkirche zu schultern ${ }^{65}$. In der Folge beschreibt Cavallini die Bedeutung der Kardinalpresbyter vor dem Hintergrund ihrer eminent gottesdienstlichen Funktionen, während den Kardinaldiakonen lediglich dienende Funktion, also eine den Kardinalpresbytern klar untergeordnete Rolle zugebilligt wird ${ }^{66}$. Soviel zum Bild, das sich ein an Santa Maria Rotonda in Rom bepfründeter Skriptor der päpstlichen Kurie von der Gliederung des Kardinalskollegs in titulis machte; ein Bild, das hinsichtlich der Aufgabenteilung nicht mehr der Wirklichkeit entsprach. Welche Bedeutung hatten römische Titelkirchen für in Avignon residierende Kardinäle, die zum überwiegenden Teil noch nie ihren Fuß in die Heilige Stadt gesetzt hatten? Welche Bedeutung hatten sie für die verleihenden Päpste?

Richtet man den Blick zunächst auf die unter Clemens VI. verliehenen Titelkirchen, so springt die durchgängige Besetzung der Kardinalbistümer ins Auge. Von Dezember 1327 bis Februar 1352 hatte Bertrand du Pouget das Bistum Ostia inne, was große Kontinuität und hohen kurial-politischen Sachverstand an der Spitze des Kollegiums garantierte. Clemens VI. besetzte im Februar 1352, also wenige Monate vor seinem eigenen Tod am 6. Dezember, dieses Bistum mit Étienne Aubert, ging somit also mit einer Geschwindigkeit vor, die auch in weiteren Fällen als Charakteristikum bei der Besetzung von Kardinalbistümern gelten darf. Nach dem Tod des Jean de Comminges Ende November 1348 wurde das Bistum von Porto und S. Ruffina im folgenden Januar mit Bernard d'Albi besetzt, nach dessen Tod im November 1350 erhielt es mit Gui de Boulogne innerhalb kurzer Zeit seinen dritten Titular ${ }^{67}$. Ähnli-

Cavallini folgt in seiner Auflistung der den Kardinalpresbytern vorbehaltenen Titelkirchen der von Petrus Mallius unter Papst Alexander III. (1159-1181) angefertigten Zusammenstellung, vgl. Walther BuCHOwIECKI, Handbuch der Kirchen Roms, Bd. 1. Die vier Patriarchalbasiliken und die Kirchen innerhalb der Mauern Roms, Wien 1967, S.35f. Zur Entwicklung der Siebenerzahl äußert sich Hans-Walter KLEwITZ, Reformpapsttum und Kardinalkolleg, Darmstadt 1957, S. 52-58; HüLs, Kardinäle, S. 8f.

64 Ed. LaUreys, III, 10, 5: Sancte Marie in Dominica; Sancte Lucie in Orto Palatii iuxta Septisolium; Sancte Marie Nove; Sanctorum Cosme et Damiani; Sancti Georgii ad Velum aureum; Sancte Marie in Cosmedin; Sancte Marie in Porticu; Sancti Nicolay in Carcere Tuliano; Sancti Eustachii; Sancte Marie in Aquiro; Sancti Theodori; Sancte Marie in Via Lata; Sancte Agathe; Sancte Lucie in Capite Suburbe vel inter ymagines; Sancti Adriani; Sanctorum Sergii et Bachi.

65 Ibid., III, 10, 6: [...] Post papam totius ecclesie onera ferre debent et oves languidas et populi peccata super ipsorum humeris portare tenentur.

${ }^{66}$ Ibid., III, 10, 8: [...] dictorum cardinalium presbyterorum ministri, qui electi sunt et assumpti ad servitium altaris.

${ }^{67}$ Gui de Boulogne war zum Zeitpunkt seiner Translation lediglich Subprior der Kardinalpresbyter. Da er als ehemaliger Erzbischof von Lyon im Gegensatz zum Prior, dem cardinalis Montisolivi, jedoch über die Bischofsweihe verfügte, wurde er diesem vorgezogen, vgl. Dykmans, Cérémonial II, S. 492. 
ches geschah im Bistum von Albano: als Gaucelme de Jean im August 1348 starb, dauerte es nur knappe drei Monate, bis mit Élie Talleyrand ein neuer Titular ernannt war ${ }^{68}$. Im Bistum Sabina folgte 1348 nach einer Vakanz von drei Monaten Bertrand de Deux auf Pedro Gomez ${ }^{69}$, im Bistum Tusculum 1350 Guillaume Court auf Annibaldo Ceccano. Keiner der so Ausgezeichneten erlangte im ersten Anlauf, d.h. im Zuge der Kardinalskreation selbst, ein Kardinalbistum. Dies deutet auf das Bemühen Clemens' VI. hin, nur erfahrene Purpurträger zu Kardinalbischöfen zu machen. Tatsächlich hatten sowohl Bernard d'Albi, Élie Talleyrand, Gui de Boulogne und Bertrand de Deux als auch Guillaume Court zuvor ihr politisches Können und diplomatisches Geschick auf wichtigen Legationen unter Beweis gestellt. Karriereambitionen wurden also nicht unmittelbar befriedigt. Die von Clemens VI. ernannten Kardinalbischöfe warteten im Durchschnitt zehn Jahre auf ihre Translationen $^{70}$, die allesamt von Presbytertiteln aus erfolgten ${ }^{71}$. Gute Aussichten auf ein Kardinalbistum hatten die ältesten Kardinalpresbyter - eine Feststellung, die von den päpstlichen Zeremonienbüchern gestützt wird ${ }^{72}$. Ein irgendwie gearteter Anspruch auf ein Kardinalbistum bestand freilich nicht. Unterschiedliche Ausnahmeregelungen konnten geltend gemacht werden. So waren beispielsweise Kardinalpresbyter, die sich auf Legationen bewährt hatten, ohne Berücksichtung des Kreationsdatums vorzuziehen ${ }^{73}$. Des weiteren sollten mögliche Kandidaten für eine Translation bereits über die Bischofsweihe verfügen ${ }^{74}$.

68 Die Promotion vom Rang des Kardinalpriesters in den des -bischofs folgte in diesem Falle den Geboten der Anciennität: Talleyrand war 1348 der - vom Zeitpunkt der Kreation aus gerechnet - älteste Kardinalpriester, vgl. ZACOUR, Talleyrand, S.17. Zur Regel sollte dieses Vorgehen erst in späteren Zeiten werden, vgl. JoRdAN, Sacré Collège, S. 429-434.

69 Im Zeremoniale fand die Tatsache Erwähnung, daß Bertrand de Deux aufgrund der während seiner Abwesenheit von der Kurie vorgenommenen Translation - er übte sein Legatenamt in Neapel aus - auf die Verleihung des Bischofsringes durch den Papst verzichten mußte, vgl. DykMaNs, Cérémonial II, S. 493.

70 Élie Talleyrand: 17 Jahre; Étienne Aubert: 10 Jahre; Bernard d'Albi: 10 Jahre; Gui de Boulogne: 8 Jahre; Bertrand de Deux: 10 Jahre; Guillaume Court: 12 Jahre. Alle Aussagen stützen sich auf Konrad EuBEL, Hierarchia catholica medii aevi, Bd.1, Regensburg 1913, I, S. 1-60.

71 Für die gesamte Zeit des Avignonesischen Papsttums können lediglich zwei Beispiele einer Translation innerhalb desselben ordo angeführt werden. Bertrandus Atgerius erhielt im Mai 1371 den Presbytertitel S. Prisce und wechselte 1375 zum Titel S. Cecilie, Lucas de Flisco wurde im März 1300 Kardinaldiakon von S. Maria in Via Lata und wechselte 1306 zur Diakonie SS. Cosmae et Damiani.

72 Dykmans, Cérémonial II, S. 489-494.

73 Im Zeremoniale wird als Beispiel für eine Bevorzugung aufgrund legatorischer Tätigkeit die Person des Bertrand de Pouget angeführt, den zum Zeitpunkt seiner Translation zwei Kardinalpresbyter an Anciennität übertrafen, vgl. ibid., S. 490.

74 Ibid., S. 489-492. Die im Falle von Gaucelme de Jean gemachte Ausnahme ist dem Zeremoniale eine eigene Rubrik wert, ibid., S.492: Notandum tamen est quod, tempore predicti domini Iohannis pape, dominus Gaucelmus Iohannis, presbiter cardinalis, licet non fuisset electus neque consecratus in episcopum vel archiepiscopum, fuit factus episcopus Albanesis. 
Unter den Presbytertiteln gab es einige wenige, die offensichtlich von besonderer Bedeutung für Clemens VI. waren, darunter S. Martini in Montibus, S. Sabine, S. Susanne und S. Vitalis, die während seines Pontifikates zweimal besetzt wurden. Eine besondere Bevorzugung einzelner, unterschiedlichen Patriarchalbasiliken zugeordneter Siebenergruppen läßt sich jedoch nicht konstatieren. Von den 25 von Clemens ernannten Kardinälen wurden $19 \mathrm{zu}$ Kardinalpresbytern kreiert, lediglich sechs mußten sich mit einer Diakonie zufriedengeben. Auffällig ist, daß es während des Pontifikates Clemens' VI. keinem der Kardinaldiakone vergönnt war, in höhere ordines aufzusteigen, deren innerkardinalizische Karriere also bereits mit der Ernennung zum Kardinaldiakon beendet war ${ }^{75}$. Das von Cavallini erwähnte Amt des Erzdiakons, das an den Titel S. Mariae in Domnica gekoppelt war, wurde während des Exils der Päpste in Avignon überhaupt nicht besetzt. Auch die Diakonien S. Agathae, SS. Cosmae et Damiani, S. Marie in Porticu, S. Nicolai in Carcere Tulliano und SS. Sergii et Bachii blieben unter Clemens VI. vakant. Im Bereich der Presbyterate galt dies für die Titel S. Eusebii, S. Laurentii in Lucina, S. Marcelli, S. Pudentiane und SS. Nerei et Achillei. Letzteren Titel hatte Clemens VI. vor seiner Erhebung zum Papst innegehabt. Die Titelkirche S. Chrysogoni stellte insofern einen Sonderfall dar, als sie im untersuchten Zeitraum lediglich als Kommende vergeben wurde. Kardinal Gui de Boulogne besa $\beta$ diese Kirche zeitgleich zu seinem Titel S. Cecilie. Für den Zeitraum von 1305 bis 1378 zeigt sich, daß der Besitz eines bestimmten Titels die Wahlchancen im Konklave weder vergrößerte noch minderte. Johannes XXII. war zuvor Bischof von Porto und S. Ruffina, Innozenz VI. Bischof von Ostia, Benedikt XII. Kardinalpresbyter von S. Prisca, Gregor XI. Kardinaldiakon von S. Maria Nova. Mögen die kardinalizischen tituli für die Entscheidungsfindung innerhalb des Konklave irrelevant gewesen sein, so zeigt sich aber doch beim Blick auf die Titelprovenienzen der zwischen 1305 und 1378 zu Kardinalbischöfen Promovierten, da $B$ der Aufstieg von einigen Presbytertiteln aus besser gelang. Den Spitzenwert liefert dabei S. Vitalis, die Titelkirche, von der aus immerhin fünf der 50 Kardinalbischöfe promoviert wurden, gefolgt von den Presbyteraten SS. Nerei et Achillei und SS. Johannis et Pauli mit jeweils vier und S. Cecilie mit drei Nennungen. Den stadtrömischen Adelsgeschlechtern der Orsini und Colonna gelang es, einzelne tituli für ihre Familie zu reklamieren. Im Falle der Orsini war dies die Diakonie S. Adriani, die von 1288 bis 1374 von nur zwei Vertretern der Familie besetzt wurde ${ }^{76}$. Im Falle der Colonna handelte es sich um die Diakonie S. Angeli in Foro Piscinum ${ }^{77}$. Ein der

75 Translationen von einer Diakonie auf ein Bistum lassen sich für die Zeit von 1305-1378 nicht nachweisen.

76 Napoleone Orsini (1288-1342) und Rainaldus Orsini (1350-1374).

77 Pietro Colonna (1306-1326) und Giovanni Colonna (1327-1348). In der Auflistung des Johannes Cavallini taucht dieser Titel nicht auf, vgl. BucHOWIECKI, Handbuch 1, S.384-391. 
Titelkirchenzuweisung zugrundeliegendes System ist zumindest für die Zeit des Avignonesischen Papsttums allerdings nicht auszumachen.

Höflichkeitsregeln, die den gegenseitigen Umgang im Konsistorium erleichtern und der gegenseitigen Wertschätzung sinnfällig Ausdruck verleihen sollten, wurden beachtet. Dazu gehörte es beispielsweise, daß die Kardinäle, sobald sie vom Papst mit Fratres angeredet wurden, ihr Birett abzunehmen hatten. Gleiches galt für den Beginn einer päpstlichen Predigt oder für die Bekanntgabe einer Entscheidung, die de fratrum consilio erging ${ }^{78}$. Diese stereotype, in fast allen päpstlichen Entscheidungen anzutreffende Formel, die im 12. Jahrhundert keinen unmaßgeblichen Rat, sondern einen rechtlich relevanten Konsens bezeichnet hatte, war im 14. Jahrhundert zum bloßen Topos herabgesunken ${ }^{79}$. Der Rat der Kardinäle wurde zwar eingeholt, mitunter sogar geschätzt, schränkte die Päpste in ihrer absoluten Entscheidungsfreiheit jedoch nicht ein. Daß es mitunter zu Streitigkeiten, ja zu harten Auseinandersetzungen innerhalb des Kollegiums kommen konnte, ist auch für den Pontifikat Clemens' VI. belegt ${ }^{80}$. Spektakulär war das Aufeinandertreffen der Kardinäle Jean de Comminges und Élie Talleyrand de Périgord. Ersterer, dessen wortgewaltige Interventionen auch unter Johannes XXII. und Benedikt XII. bezeugt sind ${ }^{81}$, klagte Talleyrand 1345 offen der Mitwisserschaft am Tode des Andreas von Ungarn an, was zu tumultartigen Zuständen im Konsistorium führte ${ }^{82}$. Ein Streit um die Predigttätigkeit der Mendikanten entzweite 1351 Papst und einige Kardinäle. Die Auseinandersetzung wurde durch ein Machtwort des Papstes zugunsten der Mendikanten entschie-

78 DyKmans, Jacques Stefaneschi, S. 548: Semper, si dirigit sermonem papa ad cardinalem, dicendo aliquid quasi debeat attente et familiariter eis aliquid dicere, consueverunt cardinales in principio sermonis pape vel dicti, birretum deponere. Si dictum protenditur, reponunt [...]. Quandocumque papa, sive in publico, sive in consistorio privato, vel alibi, vocat cardinales, Fratres dicendo mei vel De fratrum consilio, vel similia, vel Domini, cardinales semper deponunt birretum cum caputio.

79 Vgl. zur Formel Volkert PFafF, Die Kardinäle unter Papst Coelestin III., in: ZRGK 41 (1955) S. 58-94, hier S. 70-72; Harry BressLAU, Handbuch der Urkundenlehre, Bd. 2, Berlin ${ }^{4} 1968$, S. 57f. Auf die zeremonielle Bedeutung der Formel verweist DyKMANs, Stefaneschi, S. 542; vgl. auch Norman ZACOUR, The cardinals' view of the papacy, 1150-1300, in: The religious roles of the papacy: Ideals and Realities 1150-1300, hg.v. Christopher RyAN, Toronto 1989 , S. 413-439.

${ }^{80}$ Freilich fehlen für diesen Zeitraum die für den Pontifikat insbesondere Johannes' XXII. so ergiebigen Berichte der aragonesischen Gesandten. Sie stellen eine Fundgrube bezüglich der "zwischenmenschlichen« Komponente kurialer Politik dar, vgl. Acta Aragonensia, hg. v. Heinrich FINKE, 3 Bde., Berlin, Leipzig 1908-1922.

81 Vgl. Baluze/Mollat, Vitae II, S. 255.

82 Vgl. Duchesne, Histoire, S. 470; heranzuziehen ist auch die Weltchronik des Mönchs Albert, hg.v. Rudolf SPRANDEL, München 1994 (MGH SS n.s., 17), S.110: Rex Apulie Andreas, frater regis Ungarie, in lecto dormiens cum uxore sua strangulatus fuit conscia consorte. Hoc flagitium multi emuli papae et quattuor cardinalibus imponunt, de quo se papa expurgat in die cene [...]; ZACOUR, Talleyrand, S. 20-26; WoOD, Clement VI, S. 109. 
den ${ }^{83}$. Auch die Auseinandersetzung der Kurie mit Giovanni Visconti um den Besitz Bolognas zeigte ein in der Sache gespaltenes Kardinalskolleg, dessen Opposition der Papst jedoch nicht weiter beachtete ${ }^{84}$.

Das Konklave selbst mochte zwar die exklusivste Tätigkeit der Kardinäle begründen - die Papstwahl -, bedeutete jedoch aufgrund der äußeren Voraussetzungen eine enorme physische Belastung. Auf die Erleichterung des auf Gregor X. zurückgehenden Konklavereglements zielte denn auch eine Verfügung Clemens' VI., durch die den Kardinälen nicht nur ein Mindestmaß an Privatsphäre, sondern auch eine im Vergleich zur Vorgängerbestimmung bessere Nahrungsversorgung garantiert wurde ${ }^{85}$. Ob die gemäß Mt $16,18 \mathrm{f}^{86}$ an die Person des Papstes gekoppelte Binde- und Lösegewalt im Laufe des Konklave allerdings von den Kardinälen dem neuen Pontifex übertragen wurde, das Kollegium also als eigenständiges Rechtssubjekt und nicht nur als bloßes Instrument göttlichen Willens handelte, war auch um die Mitte des 14. Jahrhunderts heftig umstritten ${ }^{87}$. Clemens VI. vertrat den festen Standpunkt, daß

83 Richard Lescot, Chronique, hg.v. Jean Lemoine, Paris 1896, S.89: Anno Domini MCCCLI, in curia Romana, quidam domini cardinales cum nonullis aliis prelatis Summo Pontifici multis persuaverunt mediis ut mendicantibus inhiberet ne de cetero predicarent vel confessiones audirent ut sic eorum ordines tractu temporis penitus annullarentur, sed papa mendicantibus favendo ipsos prelatos multis rationibus redarguit finaliter sic concludens: "Vos in quid odio et sine causa comoti contra ipsos venistis sicut una congregatio taurorum in vaccis populorum ut excludatis eos qui probati sunt argento " et sic tandem respiscerunt $a b$ incepto. Vgl. Wood, Clement VI, S.98; Janet Coleman, FitzRalph's Antimendicant "proposicio« (1350) and the politics of the papal court at Avignon, in: Journal of Ecclesiastical History 35 (1984) S. 376-390.

84 Matteo Villani, Cronica, ed. PorTa, lib. 2, c. 66: Il papa nonistante ciò favoreggiava oltre al modo onesto la causa del tiranno, onde per alcuno cardinale ne fu cortesemente ripreso; a costui e alli altri cardinali che mostravano in concestoro essere zelanti dell'onore di santa Chiesa, procedendo il tempo, collo ingegno e coll'arte e co'doni degli altri furono rachiuse le bocche, e aperte le lingue in suo favore, sicché ultimamente pervenne alla sua intenzione, come seguendo al suo tempo dimosteremo; Teilübersetzung bei FENG, Devil's letters, S. 301.

85 Ob tatsächlich eine lebensbedrohende Erkrankung des Papstes Auslöser für die Neuregelung war, muß dahingestellt bleiben, vgl. hierzu Annales ecclesiastici, Bd.25, a.a. 1351, S. 523: Vergente anno Clemens correptus gravissimo morbo, parto ex maligno humore, quo suffusa facies admodum intumuit, et in discrimen salutis adductus, ex quo tamen evasit, ut felicius ad piam mortem se compararet, exemplo Joannis XXII, edito Diplomate promulgavit, a se omnia, si quae forsitan ante adeptum Pontificatum vel eo gesto non consentientia cum fide Catholica ex linguae praecipitis lapsu protulisset, revocari [...]. Consulturus etiam tum futuri successoris electioni celebrandae, Constitutionis a Gregorio X latae vigorem temperavit, sanxitque ad cardinalium gratiam, ut in conclavi famulum haberent, atque eorum mensae unum ferculum carnium vel piscium apponeretur; BALUZE/MOLLAT, Vitae I, S.257, 269-270, 285; Wood, Clement VI, S. 97.

86 Mt 16,18f.: Tu es Petrus et super hanc petram aedificabo ecclesiam meam, et portae inferi non praevalebunt adversum eam, et tibi dabo claves regni caelorum, et quodcumque ligaveris super terram erit ligatum in caelis, et quodcumque solveris super terram erit solutum in caelis. 87 Konrad von Megenberg, Ökonomik, III.3, hg. v. Sabine KRÜGER, S.365: Licet autem cardinales electores sint domini pape, non tamen sibi auctoritatem apostolicam conferunt, 
er alleiniger Inhaber der plenitudo potestatis innerhalb der Gesamtkirche sei, Kardinäle ihm also nicht bei-, sondern klar untergeordnet seien ${ }^{88}$. Eine derart postulierte, Vorstellungen bischöflicher Kollegialität nur bedingt beachtende Machtfülle wurde als schrankenlos begriffen ${ }^{89}$. Ein weiteres exklusives Recht der Kardinäle bestand in der Verwaltung ad interim des Heiligen Stuhls im Falle der Papstvakanz ${ }^{90}$. Auch hier war heftig umstritten, wie weit die von den Kardinälen in der papstlosen Zeit entfaltete Eigeninitiative reichen durfte, ohne in die Rechte des zu wählenden Papstes einzugreifen. Weitgehende Verfügungsrechte konzedierte ihnen Augustinus Triumphus in seiner zwischen 1308 und 1315 entstandenen Schrift De potestate collegii mortuo papa ${ }^{91}$. Er stieß mit seinen Aussagen jedoch auf den erbitterten Widerstand von potentiellen Gegnern einer allzu großen Machtfülle auf Seiten der Kardinäle ${ }^{92}$.

Prout moris est de iure - allein mit diesem Oxymoron läßt sich die rechtliche Stellung der Kardinäle in ihrem Verhältnis zum Papst umschreiben ${ }^{93}$. Insbesondere für Clemens VI. bestand keinerlei Zweifel daran, daß er zur Exe-

nisi organice et instrumentaliter. A Deo namque immediate et principaliter est summi pontificis auctoritas pontificalis et eius potestas. Schlichtere Gemüter wie die Wiener Begine Agnes Blannbekin (gest. 1315) gingen davon aus, daß die Papstwahl ein Tummelplatz menschlicher Eitelkeiten sei, vgl. Leben und Offenbarungen der Wiener Begine Agnes Blannbekin, hg.v. Peter DinZELBACHER und Renate VoGELER, Göppingen 1994, c. 185 , S.384-386, hier S.386: Anima tua conformat se sanctae matri ecclesiae, quae modo in desolatione est, quia caret capite apostolico; et hi, qui habent providere de capite apostolico, simoniaci haeresi vitiati sunt in eo, quod quilibet in electione apostolici ad suam respicit utilitatem volens suum amicum praeficere, et non quaerunt commune bonum et sic sunt divisi.

${ }^{88}$ Dies faßt Konrad von Megenberg in das Bild der Sonne und der umgebenden Planeten, die ihre Strahlkraft allein der Existenz der Sonne verdankten, vgl. Konrad von Megenberg, Ökonomik, III.3, hg.v. Sabine KRÜGER, S.389. Die Kardinäle werden zu hii mundi intercessores ad vicedeum, quibus primo mundus exponit indigencias suas apud sedem apostolicam evacuandas; vgl. auch Walter UlLMAN, Medieval papalism. The political theories of the medieval canonists, London 1949; Friedrich KEMPF, Die päpstliche Gewalt in der mittelalterlichen Welt, in: Saggi storici intorno al papato dei professori della Facoltà di Storia Ecclesiastica, Rom 1959, S. 117-169.

89 Vgl. Ludwig Buisson, Potestas und caritas. Die päpstliche Gewalt im Spätmittelalter, Köln, Graz 1958.

90 Vgl. Kap. 5.1.3.

91 Vgl. Alberigo, Cardinalato, S. 122; William Mulder, De potestate collegii mortuo papa des Augustinus Triumphus, in: Studia catholica 5 (1928/1929) S. 40-60.

92 Zu nennen sind hier Johannes von Paris (De potestate regia et papali), Petrus de Paludis (De potestate papae), Alvarus Pelagius (De planctu Ecclesiae) und Wilhelm von Ockham (Dialogus de potestate pape et imperatoris), vgl. WooD, Clement VI, S. 103f.; nach wie vor unterschätzt wird GUILlAUME DE PIERRE Godis, The theory of papal monarchy in the $14^{\text {th }}$ century. Tractatus de causa immediata ecclesiastice potestatis, hg. v. William David MCCREADY, Toronto 1982 (Studies and Texts, 56).

93 Eine umfassende Darstellung der Bedeutung von ius und mos für das Kardinalskolleg steht noch aus. Untersucht wurde dieses Spannungsverhältnis in Hinblick auf die Orden, vgl. Alain Boureau, Prout moris est de iure. Les moines et la question de la coutume, in: Revue historique 618 (2001) S. 363-402. 
kutive des Kardinalskollegs nicht bedürfe ${ }^{94}$. Insofern kann es nicht erstaunen, daß nach seinem Tode die Kardinäle die wohl erste Wahlkapitulation in der Geschichte der Kirche unterzeichneten ${ }^{95}$. Die Unsicherheit des Gewohnheitsrechts sollte in die Sicherheit einer jurisdiktionell festgelegten Teilhabe an der Macht überführt werden. Ob es sich dabei jedoch um die Legalisierung eines Ist-Zustands handelte, d.h. ob die Kardinäle lediglich Rechte, in deren Besitz sie faktisch bereits seit längerem waren, nachträglich in eine juristisch verbindliche Form faßten, ist in der Forschung bis heute umstritten. Auch die gegenteilige Annahme entbehrt nicht einer gewissen Logik. Könnten die Kardinäle aufgrund der fortgesetzten Beschneidung ihrer gewohnheitsmäßigen Rechte durch einen starken, allzu sehr auf seine plenitudo potestatis pochenden Papst nicht alles daran gesetzt haben, eben diesen Rechten nach dem Tod des Papstes durch einen den Nachfolger bindenden Vertrag zum Durchbruch $\mathrm{zu}$ verhelfen? Zweifellos wurde durch alle zwölf Artikel der Konstitution die päpstliche plenitudo potestatis gemindert. Die vorliegende Untersuchung sollte verdeutlichen, welcher Grad an Plausibilität insbesondere der zweiten Hypothese zukommt ${ }^{96}$.

Kardinäle befanden sich im Schnittpunkt dreier Interessen: neben ihren eigenen galt es den Vorgaben des Papstes und denen ausländischer Mächte und Institutionen gerecht $\mathrm{zu}$ werden. Guillaume d'Aure wurde so beispielsweise vor den Karren der Interessen von Abt und Kommunität von St. Jacques in Lüttich gespannt. Ohne dem Kloster persönlich verbunden gewesen zu sein, ohne vorherige Kenntnis der klösterlichen Gravamina gehabt zu haben, wurde er vom neuen, durch Konventswahl hervorgegangenen Abt dazu aufgefordert, auf den Papst dahingehend einzuwirken, daß dieser auf die Wahrneh-

94 Genau dies hatte Jean Quidort in seinem Traktat De regia potestate et papali gefordert, vgl. Quidort, hg. v. Fritz BLEIENSTEIN, Stutgart 1969, S. 185.

95 Der Text findet sich im Bullarium romanum, Bd.3b, S.316-318; vgl. auch LuLvìs, Machtbestrebungen, S. 73-102; DERS., Machtbestrebungen des Kardinalkollegiums gegenüber dem Papsttum, S. 455-483; UllmanN, The legal validity, S. 246-279; Hans-Jürgen BeCKer, Primat und Kardinalat. Die Einbindung der plenitudo potestatis in den päpstlichen Wahlkapitulationen, in: Akten des 26. Deutschen Rechtshistorikertages, hg.v. Dieter Simon, Frankfurt a. M. 1987, S. 109-127; Mollat, Contribution, S.100-102; Woon, Clement VI, S. 104-106. Gegen die Aussagen von Lulvès grenzte sich 1913 bereits Erich Schelenz deutlich ab und relativierte die dem Kolleg von Lulvès zugestandene Machtposition, vgl. Schelenz, Studien, S.55. Freilich erlag auch er dem Hang zur Schwarz-WeißMalerei, wenn er behauptete, das Kardinalskolleg habe sich in der ersten Hälfte des 14. Jahrhunderts vornehmlich aus unbrauchbaren Männern zusammengesetzt, ibid., S. 33. Die »zufolge der Sippen- und Blutsverwandtschaft (sic!) große Geschlossenheit des Kollegs « machte Hofmann zur conditio sine qua non für die Unterzeichnung der Wahlkapitulation: auch hier hätte also ein nicht nur in Ernennungsfragen mächtiger und unabhängiger Papst zum Schulterschluß der Kardinäle untereinander beigetragen, HofMANN, Kardinalat, S. 76.

96 In diesem Sinne äußert sich auch VINCKE, Bernat Miquel, S. 148; Guillemain, Cour pontificale, S. 235; Kap. 6. 
mung seiner ihm qua kanonischem Recht zustehenden Kollationsprärogative verzichtete. Weshalb wandte man sich ausgerechnet an Guillaume d'Aure? Als Argument diente dem Abt allein der Verweis auf dieselbe Ordenszugehörigkeit und die daraus resultierende Solidarität ${ }^{97}$. Ausländische Herrscher und Kommunen setzten alles daran, sich der Unterstützung einzelner Purpurträger zu versichern. Niccolò Cappocci und Pasteur de Sarrats vertraten die Interessen Venedigs, Pedro Gomez setzte sich ebenso wie Pierre Desprez für die Belange Aragons ein, Guillaume Court galt als amicus specialis des französischen Königs. Grundsätzlich konnte davon ausgegangen werden, daß diejenigen Kardinäle, die wie Andreas Ghini Malpigli oder Étienne Aubert vor ihrer Kreation im Dienste des französischen Königs gestanden hatten oder gar aufgrund seiner Intervention ernannt worden waren, eine den Interessen der Krone Frankreichs aufgeschlossene Fraktion innerhalb des Kardinalskollegs bildeten ${ }^{98}$. Raymond de Farges, Pedro Gomez, Gaucelme de Jean und Jean Desprez galten als Vertreter der Interessen Englands. Undeutlich bleibt allerdings, wie weit der jeweilige Einfluß in der konkreten Situation tatsächlich reichte. Nach außen wurde das Bild einer unparteilich, allein zum Wohle der Gesamtkirche agierenden Kurie aufrechterhalten. Insbesondere Clemens VI. war daran gelegen, nicht nur seine eigene Unparteilichkeit, sondern auch die seiner engsten Mitarbeiter zu unterstreichen ${ }^{99}$. So intervenierte er beim französischen König zugunsten von Galhard de la Mothe, der nicht nur als anglophil galt, sondern zusätzlich Opfer einer gegen ihn bei Philip VI. angestrengten Verleumdungskampagne geworden war ${ }^{100}$. Das Verfolgen von Partikularinteressen konnte einerseits auf die Hebung der gesellschaftlichen Stellung der eigenen Familie abzielen - die von Élie Talleyrand de Périgord und Gui de Boulogne in Neapel verfolgte Politik spricht in dieser Beziehung Bände ${ }^{101}$ -, konnte andererseits aber auch zur Befriedigung des immensen Finanzbedarfs genutzt werden. Ein gegen sämtliche Mitglieder des Kardinalats gerichtetes Argument war deren luxuriöse Lebensführung. In der Tat unterstreichen die von Clemens VI. seinen Purpurträgern verliehenen Pfründenmassen, was man unter angemessener Lebensführung verstand ${ }^{102}$. Das standesgemäße Auftreten nach außen konnte unterschiedliche Formen annehmen. Von groBer Bedeutung waren die von den Kardinälen in Avignon bewohnten Paläste,

97 Vgl. Émile SCHOOLMEESTERs, Recueil des lettres adressées, pendant le XIVe siècle, aux papes et aux cardinaux pour les affaires de la principauté de Liège, in: Analectes pour servir à l'histoire ecclésiastique de la Belgique 15 (1878) S. 35-37; vgl. zum Problem des Wirkens einzelner Kardinäle als Fürsprecher ausländischer Mächte Geoffrey BARRACLOUGH, The medieval papacy, London 1968, S.158-162.

98 Vgl. hierzu Kap. 4.1.

99 Vgl. Kap. 2.

100 Vgl. Kap. 9.2.15.

101 Vgl. Kap. 5.2.2.1.

102 Vgl. zu den von Clemens VI. verliehenen Benefizien die entsprechenden Eintragungen in den Kardinalsbiogrammen, Kap. 9.2. 
die sogenannten Livréen, zu denen sich prachtvolle Sommerresidenzen, bevorzugt jenseits der Rhône in Villeneuve-lès-Avignon, gesellen konnten ${ }^{103}$. Die Finanzierung einer derart kostspieligen Lebensführung konnte nur durch die Erträge aus möglichst lukrativen Pfründen sichergestellt werden. Die Supplikenregister Clemens' VI. sind in dieser Beziehung ausgesprochen aussagekräftig. Großes Interesse hatten die Kardinäle deshalb daran, die Anzahl der Mitbrüder im Amte möglichst klein zu halten, um ihre eigenen Einkünfte und Benefizien nicht zu schmälern. Während des Pontifikats Clemens' VI. lag diese Zahl bei durchschnittlich zwanzig Personen. Kontinuierliches Ärgernis war die insbesondere bei den Kardinallegaten vorherrschende Meinung, ihre Bedeutung könne durch eine überdimensionierte Eskorte gesteigert werden ${ }^{104}$. Die Übernahme der dadurch entstehenden Kosten war selbstverständlich Sache des Klerus im jeweiligen Legationsgebiet. Übersteigerter Luxus diente in vielen Fällen dazu, die eigene eminente Position unmißverständlich vor Augen zu führen. Legendär ist der an Raffinement wohl kaum zu überbietende Empfang, den die Kardinäle Annibaldo Ceccano und Pedro Gomez dem Papst in ihren Sommerpalästen vor den Toren Avignons ausrichteten. Die Beschreibung eines anonymen Florentiner Autors schildert ein märchenhaftes Ambiente, das eher dem verfeinerten Lebensstil eines orientalischen Herrschers denn der vita evangelica der Apostel entspricht ${ }^{105}$. Der Blick wird gleichermaBen auf die Ausstattung der Räumlichkeiten, die aufgrund der Vielzahl der verwendeten Seidenstoffe wie entmaterialisiert wirken, auf die staunenswerte Variationsbreite der 27 servierten Gerichte, auf die Kostbarkeit der verteilten Geschenke und auf die Qualität des flankierenden Amusement gelenkt. Zumindest Annibaldo Ceccano demonstrierte, was er unter der Stellung eines Kirchenfürsten verstand. Der solcherart entfaltete Luxus war dem des päpst-

103 Vgl. Mollat, Contribution, S. 58-61; Norman P. ZACour, Papal regulation of cardinals' households in the fourteenth century, in: Speculum 50 (1975) S. 434-455; Anne-Marie HAYEZ, Les livrées avignonnaises de la période pontificale, in: Mémoires de l'Académie de Vaucluse, 8e série, 1 (1992) S. 93-130.

104 Singulär ist eine Notiz des Anonimo Romano, in der von einer Art Menagerie im Gefolge des 1349 in Rom anwesenden Kardinallegaten Annibaldo Ceccano gesprochen wird, vgl. Kap. 5.2.4.1.

$105 \mathrm{Vgl}$. Eugenio Casanova, Visita di un papa avignonese a suoi cardinali, in: Archivio della R. Società Romana di Storia Patria 22 (1899) S. 371-381; Georges de LoYE, Réceptions du pape Clément VI par les cardinaux Annibal Ceccano et Pedro Gomez à Gentilly et Montfavet, in: Avignon au Moyen Âge. Textes et documents, Avignon 1989, S.81-92. Eine deutsche Übersetzung liefert Gottfried KERSCHER, Architektur als Repräsentation. Spätmittelalterliche Palastbaukunst zwischen Pracht und zeremoniellen Voraussetzungen (Avignon, Mallorca, Kirchenstaat), Tübingen, Berlin 2000, S. 199-204, S. 480-483. Als Vergleichsmöglichkeit bietet sich das Krönungsmahl Clemens' VI. vom 19. Mai 1342 an, dessen einzelne Ausgabenposten die päpstlichen Rechnungsbücher detailliert aufschlüsseln, vgl. SCHÄFER, Ausgaben Klemens VI., S. 184-191. Im Laufe seines Pontifikats veranstaltete Clemens VI. eine Vielzahl von Festessen. Die Präsenz einiger oder aller Kardinäle an diesen Essen belegen die Rechnungsbücher, vgl. ibid., S. $199 f ., 262$, 264, 284f., 320, 359f., 417. 
lichen Haushalts durchaus vergleichbar ${ }^{106}$. Unbestreitbar ist die Tatsache, daß sich die in Avignon residierenden Kardinäle sozialen Zwängen hinsichtlich ihrer Lebensführung nicht entziehen konnten. Selbst ein so erbarmungsloser Kritiker wie Petrarca zeigte sich ratlos, als er 1352 von Élie Talleyrand de Périgord gefragt wurde, wie sich denn evangelisches Leben und die in seiner Position geforderte Prachtentfaltung miteinander in Einklang bringen ließen. Der Rat Petrarcas mündete in der Feststellung: »Wenn du auch nach außen nicht so sein kannst, wie du möchtest, sei wenigstens innerlich so, wie du sein sollst « 107 .

Einige Kardinäle lebten deutlich über ihre Verhältnisse. So starb beispielsweise Pedro Gomez hochverschuldet - für seine Verbindlichkeiten trat Anglic Grimoard ein ${ }^{108}$. Auch der ehemalige Generalmagister des Dominikanerordens, Gérard de Daumar, hinterließ die für den Angehörigen eines Bettelordens erstaunliche Schuldenlast von 3800 Florin $^{109}$. Angriffspunkte waren also durchaus vorhanden und fanden Eingang in ein Schreiben, für das angeblich Lucifer selbst verantwortlich zeichnete. Schenkt man dem Bericht des Florentiner Chronisten Matteo Villani Glauben, muß sich 1351 im Konsistorium Erstaunliches ereignet haben ${ }^{110}$ : Nachdem ein Kardinal unbeobachtet einen Brief fallengelassen hatte, gelangte dieser in die Hände des Papstes und wurde von ihm öffentlich verlesen. Klingen schon die Umstände, die zur Auffindung des Briefes führten ${ }^{111}$, seltsam, so war es der Absender noch viel mehr: der Teufel höchstpersönlich wandte sich mit folgenden Worten an

106 Darauf weist jetzt auch Stefan Weiss hin, der belegt, daß der Weinbedarf der Kardinalshaushalte dem des Papstes vergleichbar war, vgl. DERS., Die Versorgung des päpstlichen Hofes in Avignon mit Lebensmitteln (1316-1378). Studie zur Sozial- und Wirtschaftsgeschichte eines mittelalterlichen Hofes, Berlin 2002, S. 435; dazu auch Bernhard SCHIMMELPFENNIG, Zur Versorgung der Kurie in Avignon mit Lebensmitteln, in: Römische Kurie. Kirchliche Finanzen. Vatikanisches Archiv. Studien zu Ehren von Hermann Hoberg, hg.v. Erwin GATZ, Bd.2, Rom 1979 (Miscellanea Historiae Pontificiae, 46), S. 773-787; Yves RENOUARD, La consommation des grands vins du Bourbonnais et de Bourgogne à la cour pontificale d'Avignon, in: Annales de Bourgogne 24 (1952) S.221-244; Eugène MüNTZ, L'argent et le luxe à la cour pontificale d'Avignon, in: Revue des questions historiques 66 (1899) S. 5-44, 378-406; Roberte LENTSCH, Une commande d'orfèvrerie du pape Clément VI, in: Avignon au Moyen Âge, Avignon 1988, S. 93-95.

107 Petrarca, Familiares, 14,1; übersetzt in PIUR, Buch, S.62; vgl. dazu auch John Eveleth WRIGLEY, Pétrarque, Avignon et Rome, une interprétation, in: Genèse et débuts du Grand Schisme d'Occident, Paris 1980 (Colloques internationaux du Centre National de la Recherche Scientifique, 586), S. 233-238.

108 Baluze/Mollat, Vitae IV, S. 344.

${ }^{109}$ Lettres Clément VI, nn. 482, 1169.

110 Matteo Villan, Cronica con la continuazione di Filippo Villani, hg. v. Giuseppe PoRTA, 2 Bde., Parma 1995, hier Bd. 1, lib. 2, c. 48, S. 278f.: Di una lettera fu trovata in consistoro di papa; vgl. hierzu Louis GREEN, Chronicle into History. An Essay on the interpretation of History in Florentine fourteenth-century chronicles, Cambridge 1972, S. 77f.

111 Der Fundort selbst ist hier Bedeutungsträger, wurden doch im Konsistorium auch Fälle der »Kirchenzucht«, insbesondere das Fehlverhalten der hohen Prälaten, behandelt. 
Papst und Kardinäle: »Lucifer, Fürst der Unterwelt [...] grüßt alle Anhänger unseres Reiches, die Söhne der Hochmut, insbesondere aber die Fürsten der gegenwärtigen Kirche [...]. Wir wünschen, daß ihr unseren Befehlen gehorcht und so wie ihr begonnen habt, den Gesetzen Satans zu folgen, mögt ihr auch in Zukunft unsere rechtlichen Verfügungen niemals aus den Augen verlieren [...]. Über alle erhaben und alle·Dinge besitzend, gebt ihr weder dem Kaiser, was des Kaisers, noch Gott, was Gottes ist; nein, ihr folgt vielmehr unseren Gesetzen [...]. Ihr seid von bitterster Armut langsam zum Gipfel der Ehre und zur absoluten Spitze der Würden durch geschickte Kniffe und finstere Machenschaften aufgestiegen, durch Hypokrisie, Schmeichelei, Lug und Trug, Meineid, Verrat, Simonie und alle übrigen Schandtaten, die weiter reichen, als es unsere Schwestern, die Furien, jemals verwirklichen könnten $[\ldots] \ll^{112}$. Lucifer schildert daran anschließend typische Verhaltensweisen der Kirchenfürsten und gewährt einen detaillierten Einblick in ihr Tun und Lassen. Er fährt fort: "Ihr habt ansehnliche Paläste gebaut, voller Annehmlichkeit und Schönheit. In hemmungsloser Schlemmerei eßt ihr exquisite Speisen und trinkt edle Weine, ihr häuft unglaubliche Schätze an, nicht so wie jener, der gesagt hat: ,Silber und Gold habe ich nicht. « Ihr habt das Goldene Zeitalter ${ }^{113}$ wieder hergestellt [...]. O geliebtes Babylon, o Bürger, die ihr aus Jerusalem dorthin gekommen seid, euch lieben wir zurecht, euch spenden wir Beifall, da ihr die Gesetze des Simon Petrus vernachlässigt und anstattdessen den Gesetzen des Simon Magus, unseres Freundes, folgt $[\ldots]{ }^{114}$. Der Brief schließt mit der Aufforderung, den einmal eingeschlagenen Weg auch weiterhin zu beschreiten. Luzifer versichert die Briefadressaten seines Beistands: So wie für die Gerechten ein Platz im Himmel reser-

112 Eine kritische Edition dieses Teufelsbriefes findet sich im Anhang der Dissertation von Helen C. FENG, Devil's letters. Their history and significance in church and society, 1100-1500, PhD Northwestern University 1982, S. 353-362; vgl. des weiteren Wilhelm WaTtENBACH, Über erfundene Briefe in Handschriften des Mittelalters, besonders Teufelsbriefe, in: Sitzungsberichte der königlich-preußischen Akademie der Wissenschaften, 1892, S. 91-123; Konrad HeILIG, Zu zwei »Teufelsbriefen« des 14. und 15. Jahrhunderts, in: Historisches Jahrbuch 52 (1932) S. 495-500; Damasus TrapP, Peter Ceffons of Clairvaux, in: Recherches de théologie ancienne et médiévale 24 (1957) S. 101-154; Gianni ZIPPEL, La lettera del Diavolo al clero, dal secolo XII alla Riforma, in: Bulletino dell'Istituto storico italiano per il Medio Evo e Archivio Muratoriano 70 (1958) S. 125-179; Richard EMMERSON, Ronald HERZMAN, Antichrist, Simon Magus, and Dante's "Inferno « XIX, in: Traditio 36 (1980) S. 373-399.

113 Dieser Teufelsbrief muß der Gattung der literarischen Satire zugerechnet werden. Gemäß seiner Herkunft aus einer "Gegenwelt « wird der mythische Referent vieler politischer Satiren, das vermeintliche Goldene Zeitalter, hier in einer Umkehr zum ansonsten verdammten Beispiel für den Verfall einer Gesellschaft, deren Wandel traditionelle Normen und Wertvorstellungen mißachtet; vgl. hierzu Sophia MENACHE, Jeannine HorowITZ, Quand le rire devient grinçant. La satire politique aux XIII et XIVe siècles, in: Le Moyen Âge 102 (1996) S. 437-463.

114 Deutsche Übersetzung vom Verfasser. 
viert sei, dürften sich die Kardinäle als eifrigste Beförderer der teuflischen Sache auf Erden auf einen ausschließlich ihnen vorbehaltenen Platz in der Hölle freuen. Der anonyme Autor ${ }^{115}$ reiht sich mit seinem Brief in die Reihe all derer ein, deren satirische literarische Produktion der Kurie eine Art Spiegel vorhielt, in dem die Wirklichkeit zwar verzerrt, nichtsdestotrotz aber in groben Umrissen zu erkennen war. Den groben Umrissen entsprach im Falle des Teufelsbriefes denn auch die grobe Sprache. Das den Kardinälen abverlangte Anforderungsprofil war bekannt: gerecht sollten sie sein, gottesfürchtig, allem Hochmut und aller Habsucht abhold. Durch die Umkehrung dieser Qualitäten in ihr Gegenteil war die Stoßrichtung des literarisch geführten Angriffs eindeutig: die Diskreditierung der Purpurträger. Und tatsächlich stellt dieser Angriff neben Petrarcas Sine nomine-Briefen ${ }^{116}$ die schärfste Geißelung kardinalizischen Verhaltens während des Pontifikates Clemens' VI. dar ${ }^{117}$.

Das Patronagesystem der Kardinäle bedarf noch eingehender, prosopographisch ausgerichteter Untersuchungen. Aufgrund der Stellung Avignons als kulturelles Zentrum kann die Massierung von Intellektuellen und Künstlern in der Umgebung des Papstes und der Kardinäle kaum erstaunen. Unbekann-

115 Zur Autordiskussion vgl. FENG, Devil's letters, S. 149-160; vgl. auch Giuseppe BRIzzoLARA, I sonetti contro "L'avara Babilonia《e il "Soldano« del Petrarca, in: Studi storici 7 (1898) S. 267-288, 309-352; John Eveleth WrIGLEY, The devil and Francis Petrarch, in: The Library Chronicle 33 (1967) S. 75-96.

116 Als maßgebliche Edition gilt noch immer Paul PIUR, Petrarcas »Buch ohne Namen « und die päpstliche Kurie. Ein Beitrag zur Geistesgeschichte der Frührenaissance, Halle 1925. Von dem Bemühen, diese für die Außenwirkung der Kurie um die Mitte des 14. Jahrhunderts zentralen Texte einer breiteren (studentischen) Öffentlichkeit zugänglich zu machen, zeugen die Ausgaben von Francesco Petrarca. Sine nomine. Lettere polemiche e politiche, hg. v. Ugo DotTI, Bari 1974; Petrarch's Book without a name. A translation of the Liber sine nomine, hg. v. Norman P. ZACOUR, Toronto 1973 und Francesco Petrarca. Aufrufe zur Errettung Italiens und des Erdkreises, hg. v. Berthe WIDMER, Basel 2001; vgl. auch Cipolla, Francesco Petrarca; Giuseppe Brizzolara, Le sine titulo del Petrarca, in: Studi storici 4 (1895) S. 1-40, 447-471; Ezio RAIMONDI, Una pagina satirica delle Sine nomine, in: Studi petrarcheschi 6 (1956) S.55-61; Robert CoogAN, The nature, artistry and influence of Petrarch's Epistolae sine nomine, in: Acta conventus neo-latini Turonensis, hg. v. Jean-Claude Margolin, Paris 1980, S. 109-123; Pierre Blanc, Le discours de l'intellectuel comme parole d'exile: psycho-poétique de l'exil chez Dante et chez Pétrarque, in: Exil et civilisation en Italie (XIIe-XVIe siècles), hg.v. Jacques HeERs, Christian BEC, Nancy 1990, S. 49-59; Fred J. NicHOLS, Petrarch's Liber sine nomine and the limits of language, in: Acta conventus neo-latini Hafniensis, Binghampton 1994 (Medieval and Renaissance Texts and Studies, 120), S. 741-750. Eine Studie des Vf., die das Verhältnis zwischen Petrarca und den Kardinälen unter Clemens VI. beleuchtet, wird in Kürze erscheinen.

117 Bereits Ludwig IX. hatte das fast identische Idealbild eines Kardinals gezeichnet, vgl. Henri DELABORDE, Instructions d'un ambassadeur envoyé par Saint Louis à Alexandre IV à l'occasion du traité de Paris (1258), in: BEC 49 (1888) S.630-634, hier S. 633: Et cum fieret ordinatio, supplicat dominus rex et rogat ut tales creentur cardinales qui zelum Dei habeant, lucrum animarum affectent et avaritiam detestentur. Ipsi enim speculum honestatis et christiane sanctitatis debent ceteris prelatis tam majoribus quam minoribus ecclesie generalis. 
te Kleriker konnten wie im Falle des Pierre Thomas durch Geistesschärfe und besondere Redegabe auf sich aufmerksam machen, dadurch einem einflußreichen Purpurträger wie Élie Talleyrand de Périgord auffallen, der des weiteren den Aufstieg seines Schützlings bis hin zu einer Art Hofprediger ermöglich$t^{118}$. Die familia eines Kardinals, zu der eben nicht nur Bedienstete, sondern auch Künstler, Literaten und Musiker gehörten, konnte bis zu 50 Personen umfassen ${ }^{119}$. Dissidente Guppen durften mitunter auf Schutz aus den Reihen des Kardinalskollegs hoffen. Der Franziskaner Jean de Roquetaillade, seit 1349 in Avignon inhaftiert, stand beispielsweise in engem Kontakt zu Élie Talleyrand de Périgord, dem Protektor des Franziskanerordens, der ihm nicht nur leichtere Haftbedingungen verschaffte, sondern ihm auch den Austausch mit einigen seiner Mitbrüder und vor allem die Weiterarbeit an seinen Werken ermöglichte ${ }^{120}$.

Über die Predigttätigkeit der Kardinäle an der Kurie ist wenig bekannt. Kein Zweifel kann daran bestehen, daß sie es waren, denen gewöhnlich die vom Zeremoniell vorgesehenen Predigten coram papam oblagen. Dazu stand ihnen eine eigene cathedra zur Verfügung ${ }^{121}$. Wenn Blake Beattie nach einer Untersuchung der aus dem Zeremoniale Stefaneschis resultierenden Vorgaben behauptet, daß rund 3000 Predigten von den Kardinälen in Avignon

118 The life of Saint Peter Thomas by Philippe de Mézières, hg.v. Joachim de SMET, Rom 1954, S. 57-60: In Cathurcio autem stetit legendo, praedicando, et mirabilia faciendo per tres annos, et reversus est Parisius, ibique studuit quasi per quattuor annos, et factus est baccalarius in theologia. Reversus autem ad provinciam suam factus est procurator Ordinis sui, et venit ad curiam Romanam. Tunc generalis Ordinis / sui, existens in curia, et videns ipsum Fratrem Petrum parvum corpore et modicae apparentiae, et quod illi de provincia sua ordinaverant illum procuratorem Ordinis, despexit eum in corde suo, et nolebat ipsum ducere in praesentia cardinalium prae verecundia. Tandem motu Dei et beatae Mariae Dominus Cardinalis Petragoricensi, audiens sufficientiam suam et quod erat de provincia sua, voluit ipsum videre et eum habere in prandio. Post prandium vero fuit mota quaedam quaestio secundum usum cardinalium, ibique fuit Frater Petrus cognitus et divulgatus mirabiliter; et cognita sua magna scientia et subtilitate, postea in curia incepit praedicare et disputare taliter quod omnes mirabantur de ipso [...]. Tandem ad promotionem Reverendissimi Patris Domini Cardinalis Petragoricensis per generalem Ordinis Beatae Mariae de Carmelo ordinatum fuit quod Frater Petrus iret Parisius et cursum suum perficeret, ut posset doctorari in sacra pagina [...]. Praedicabat populo aliquando et pluries faciendo duos vel tres sermones clero et populo in uno die, collationibus cardinalium post prandium exceptis, et beatus erat ille cardinalis vel praelatus qui Fratrem Petrum Thomae in amicum domesticum et in mensam habere poterat.

$119 \mathrm{Vgl}$. Mollat, Contribution, S.50-57.

120 Vgl. VONES, Urban V., S.45f.; BIGNAMI-OdIER, Jean de Roquetaillade (de Rupiscissa), S. 99, 103; grundsätzlich Martin FABER, Frühneuzeitliche Kardinalprotektorate, in: Römische Quartalschrift 94 (1999) S. 267-275.

121 Vgl. Dominique Michel, Le Palais des Papes, in: Annales d'Avignon (1947) S. 17, wo eine Zahlung für die Anfertigung einer cathedra erwähnt wird: Pontio Berqui, fusterio de Avinione, pro cathedra lignea operata ab ipso pro capella domini nostri pape, in qua quidem cathedra domini cardinales sedent quando predicant. 
gehalten worden sein müßten, erstaunt die Überlieferungssituation um so mehr ${ }^{122}$. Lediglich eine Handschrift, Valencia cat. bib. MS 215 (olim 258), überliefert 33 an der avignonesischen Kurie gehaltene Predigten, von denen immerhin fünf von Kardinälen stammen ${ }^{123}$. Der Verfasser konnte eine weitere, von Bertrand du Pouget stammende Predigt identifizieren ${ }^{124}$. Auch wenn man davon ausgeht, daß sehr viele der eigentlich von Kardinälen zu haltenden Predigten von anderen Klerikern ausgeführt wurden, bleibt die Frage, weshalb die Überlieferungschancen für kardinalizische sermones derart schlecht waren. Ein reiner Überlieferungszufall kann vor dem Hintergrund rein numerischer Größe wohl ausgeschlossen werden ${ }^{125}$. Eher wäre an einen Verlust aufgrund mangelnder sermonialer Qualität zu denken. Im Falle Clemens' VI. ist die breite Überlieferung maßgeblich auf die Verwendung vieler sermones als Musterpredigten zurückzuführen. Vorbildliches Predigen scheint jedoch gerade für die Juristenkardinäle ein unerreichbares Ziel gewesen zu sein ${ }^{126}$. Der mitunter jahrhundertelang währende SelektionsprozeB, der die Spreu vom Weizen trennte, scheint vor den Predigten der Purpurträger nicht haltgemacht $\mathrm{zu}$ haben. Noch die älteren Kardinalsbiographien verzeichnen mitunter sermones, die freilich die Zeitläufte nicht oder zumindest nicht unter ihrem tatsächlichen Verfassernamen überdauert zu haben scheinen. Nicht nur die coram papam gehaltenen Predigten müssen größtenteils als verloren gelten, auch von den während der Legationsreisen gehaltenen sermones haben sich nur wenige Spuren erhalten. Ebensowenig wurden die

122 Blake BEATTIE, The preaching of the cardinals at papal Avignon, in: Medieval Sermon Studies 38 (1996) S. 17-37; DERS., Coram papa preaching and rhetorical community at papal Avignon, in: Preacher, sermon and audience in the Middle Ages, hg. v. Caroline MuEsSIG, Leiden 2002, S.63-88; dazu auch Thomas KAEPPELI, Predigten am päpstlichen Hof von Avignon, in: AFP 19 (1949) S.388-393; Jacques Guy BoUgEROL, La Papauté dans les sermons médiévaux français et italiens, in: The religious roles of the papacy. Ideals and Realities 1150-1300, hg. v. Christopher RYaN, Toronto 1989, S.247-277.

123 Es sind dies Pierre Desprez (Vox clamantis in deserto), Pierre Bertrand senior (Sanctificamini in iusticia), Imbert Dupuy (Si vis, faciamus hic tria tabernacula), Élie Talleyrand de Périgord (Si in digito Dei eicio demonia) und Gui de Boulogne (Hec est enim voluntas Dei).

124 Der Sermo Erat Jhesus eiciens findet sich in einer im Pembrok College zu Cambridge aufbewahrten Handschrift, vgl. Montague-Rhodes JAMES, A descriptive catalogue of the manuscripts in the Library of Pembrok College Cambridge, Cambridge 1905, n. 98, fol.94v-98v; vgl. dazu Blake BEATTIE, A curial sermon by cardinal Bertrand du Poujet, in: Medieaval Studies 67 (2005) S. 75-98; Kap. 5.1.10.

125 Arnold EsCH, Überlieferungs-Chance und Überlieferungs-Zufall als methodisches Problem des Historikers, in: Ders., Zeitalter und Menschenalter. Der Historiker und die Erfahrung vergangener Gegenwart, München 1994, S. 39-70.

$126 \mathrm{Vgl}$. Blake BEATTIE, Lawyers, law and sanctity in sermons from papal Avignon, in: Models of holiness in medieval sermons, hg.v. Beverley M. KIENZLE, Louvain-la-Neuve 1996, S. 259-282; Bernard Guillemain, Les juristes à la cour pontificale d'Avignon, in: Liber amicorum. Études offertes à Pierre Jaubert, hg.v. Gérard AuBIN, Bordeaux 1992, S. 327-334. 
zu Ehren der Patrone der jeweiligen Titelkirchen entstandenen Predigten überliefert ${ }^{127}$.

Über den Tod der an der Kurie verstorbenen Kardinäle ist recht wenig bekannt. Die erhaltenen testamentarischen Verfügungen künden von dem Wunsch nach einem würdigen, nicht zwangsläufig kostspieligen Begräbnis. Als letzte Ruhestätte bestimmte man zumeist von den Erblassern gegründete Klöster ${ }^{128}$. Für den Pontifikat Clemens' VI. war es allein der 1349 in legationibus erfolgte Tod des Annibaldo Ceccano, der auf äußere Einwirkungen zurückgeführt wurde und Anlaß zu Gerüchten und Unterstellungen gab ${ }^{129}$. Kardinal Gérard de Daumar konnte nur aufgrund der Großherzigkeit des Papstes, der den Testamentsexekutoren 1500 Florin zusätzlich zur Verfügung stellte, in seinem testamentarisch verfügten Begräbnisort in der Dominikanerkirche zu Brive beigesetzt werden ${ }^{130}$. Für den Großteil der unter Clemens VI. agierenden Kardinäle war der Tod ebenso unspektakulär wie ihre kuriale Existenz.

127 Stefaneschi macht, zugeschnitten auf seine Kardinaldiakonie S. Georgio in Velabro, in dem von ihm verfaßten Officium in festo Sancti Georgii martyris folgende Bemerkung: [...] et prosequitur sermonem suum in latino, quia multi inibi prelati et doctores et magistri in theologia et magni viri clerici esse consueverunt, vel in vulgari prosequitur, si hoc multitudo populi requirat, DYKMANS, Stefaneschi, S. 536-554, hier S. 551.

128 Vgl. Peter LEX, Das kirchliche Begräbnisrecht historisch-kanonistisch dargestellt, Regensburg 1904; Dieter SCHÄFER, Mittelalterlicher Brauch bei der Überführung von Leichen, in: Sitzungsberichte der Preussischen Akademie der Wissenschaften, 1920, S. 478-498; Armand Bernard, La sépulture en droit canonique du décret de Gratien au concile de Trente, Paris 1933; Elisabeth BROWN, Death and the human body in the Later Mittle Ages: the legislation of Boniface VIII on the division of the corpse, in: Viator 12 (1981) S. 221-270; Francesco SANTI, Il cadavere e Bonifacio VIII, tra Stefano Tempier e Avicenna. Intorno ad un saggio di Elisabeth Brown, in: Studi medievali 28 (1987) S. 861-878. Die Verfügung Bonifaz' VIII. findet sich bei FrIEDBERG, II, Sp. 1271-1273.

129 Vgl. Kap. 5.2.4.1.

130 Lettres Clément VI, nn. 482, 1169. 